NASA Technical Memorandum 84369

NASA-TM-8436919830018881

\title{
Interaction of Multiple Supersonic Jets with a Transonic Flow Field
}

Arnan Seginer, Jonah Manela

May 1983

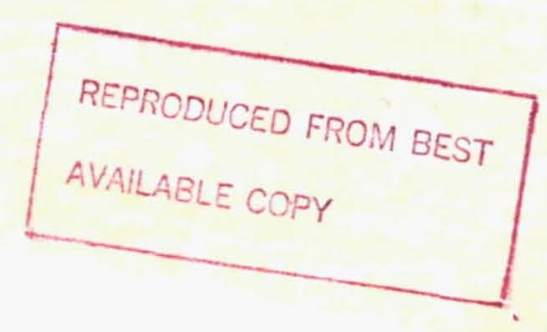

\section{LIBRARY GOPY}

U 201983 


\section{Interaction of Multiple Supersonic Jets with a Transonic Flow Field}

Arnan Seginer, Ames Research Center, Moffett Field, California

Jonah Manela, Armaments Development Authority, Box 2250, Haifa, Israel 
INTERACTION OF MULTIPLE SUPERSONIC JETS WITH A TRANSONIC ELOW EIELD

Arnan Seginer*

NASA Ames Research Center, Moffett Field, Calif. 94035

and

Jonah Manela-

Armaments Development Auchority, Box 2250, Haifa, Israel 31021

\section{Abstract}

The influence of multiple high-pressure, supersonic, radial or tangential jets, that are injected from the circumference of the base plane of an axisymmetric body, on its longitudinal aerodynamic coefficients in transonic flow is studied experimentally. The interaction of the jets with the body flow field increases the pressures on the forebody, thus altering its lift and static stability characteristics. It is shown that, within the range of parameters studied $\left(0.7 \leq M_{\infty} \leq 1.05\right.$; $\left.20 \leq p_{o j} / p_{\infty} \leq 70 ; 0^{\circ} \leq \alpha \leq 18^{\circ}\right)$, this interaction has a stabilizing effect on the body. The contribution to lift and stabllity is significant at small angles of attack and decreases nonlinearly at higher angles when the crossflow mechanism becomes dominant. The experimental results, obtained with several injection pressure ratios, are correlated using a newly defined jet penetration height into transonic flow. An equivalent flare (or skirt) is proposed for an approximate engineering prediction of the normal force and of the position of the center of pressure.

\section{Nomenclature}

$A=$ throat cross-section area of injection nozzles (Eq. (12))

$C_{D}=$ drag coefficient, $D / q S$

$c_{j}=$ nozzle discharge coefficient, $\dot{\mathrm{m}}_{j} / \rho_{j} \mathrm{~V}_{j} \mathrm{~A}_{j}$

$C_{N}=$ normal force coefficient, $N / q S$

$C_{p}=$ pressure coefficient, $\left(p-p_{\infty}\right) / q$

$\mathrm{d}=$ nozzle diameter

D = body diameter, also drag

$h=j e t$ penetration height

$M=$ Mach number

$\dot{\mathrm{m}}=$ mass $\mathrm{flux}$

$\mathrm{N}$ = normal force

$n=$ number of jets

$\mathrm{p}=$ pressure

*NRC Senior Research Associate. On leave from Technion-Israel Institute of Technology. Member AIAA.

- Research Scientist.

This paper is declared a work of the U.S. Government and therefore is in the public domain.

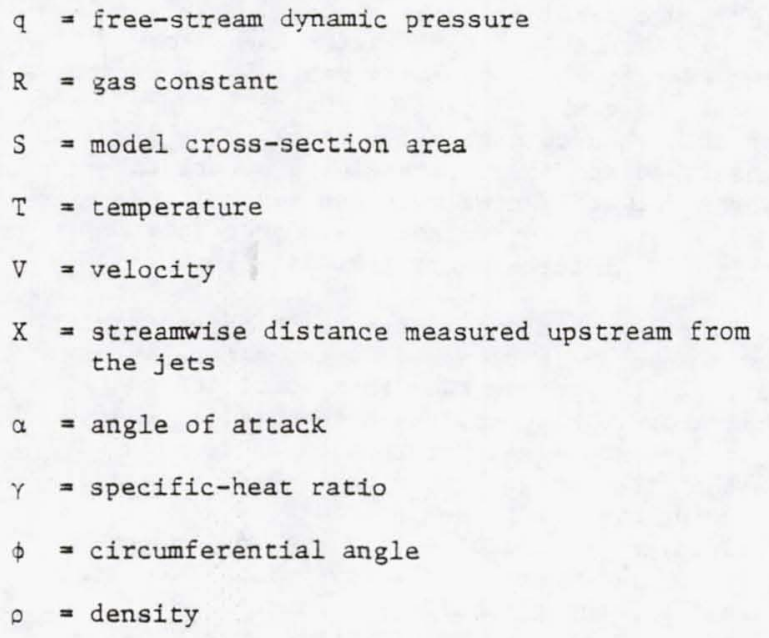

Subscripts

$\mathrm{CP}=$ center of pressure

$j$ - jet parameters

0 = stagnation conditions

$t=$ nozzle throat parameters

$\infty$ = free-stream conditions

$\underline{\text { Introduction }}$

Attention was first focused on the interaction of jets with external flow fields in the early fifties, with the advent of jet-propelled vehicles and the beginning of the space program. In jet and rocket propulsion, the jet is approximately aligned with the external flow field and the interaction between them is relatively simple. More complicated is the problem of a jet that is not aligned with the outer flow, such as retrojets or transversal jets. This latter type of interaction can be found in short takeoff and landing (STOL) aircraft, in thrust vector control, and in direct vehicle-attitude control. It is characterized by an effective jet thrust that is larger than the conventional thrust, obtained by blowing into a stagnant medium, as a result of its interaction with the surrounding flow field. Early studies of this transonic-flow interaction phenomenon concentrated on the interaction of a single, usually sonic, and two-dimensional jet with an external supersonic flow. Most studies were experimental because of the complexity of the problem. A few simple analytical, semi-empirical and numerical methods were also introduced at a later stage. These methods required, however, many simplifying assumptions and were, therefore, limited to a small group of problems. 
A represencative study of a two-dimensional interaction of a supersonic planar flow with a cransversal sonic jet was published by Spaid and Zukoski. ${ }^{2}$ The typical features of the interaction flow field are shown in Fig. 1 (taken from Ref. 1). The jet acts as an obstacle to the main flow, generating a shock wave and forcing the flow to separate and lift off the suriace in order to negotiace the obstacle. The separation shock generates a sharp pressure rise, Eollowed by a pressure placeau. A bow shock that forms near the jet causes an additional pressure rise after the plateau. The jet is bent aft by the high-pressure region and a lowpressure separation region forms behind it. Farther downstream, the combined jet and outer flows reattach through a recompression shock. The flow field described in Fig. I resembles a supersonic flow over a forward-facing step and several investigators ${ }^{2-4}$ ised an equivalent solid body to simulate the jet's disturbance to the main flow.

The three-dimensional interaction of a circular jet with a supersonic planar flow is, generally speaking, similar to the two-dimensional interaction described above. However, the extent and intensity of the three-dimensional interaction is reduced because the flow can go around the obstacle in addition to going over it. The interactions of a single circular jet and of multiple circular jets with a planar flow were studied by Spaid, Zukoski, and Rosen, 5 and their results are summarized in? Ref. 6. Typical pressure distributions in the vicinity of a single jet and of a pair of jets are shown in Fig. 2 (taken from Ref. 5).

Spaid and Cassel's contention was that the following parameters governed the interaction of jets with a uniform flow and have to be carefully simulated in any experiment ${ }^{6}$ :

1) The geometry of the model and injection ports

2) The main-flow Mach and Reynolds numbers

3) The ratio of specific heats of the injectant

4) Injection pressure ratio $\left(\mathrm{p}_{0 j} / \mathrm{p}_{\infty}\right)$

5) Total-temperature and molecular-weight ratio

However, Chrans and Collins ${ }^{7}$ showed that hot jets could be simulated by cold-flow experiments. They found no influence of the jet's total temperature or molecular weight on the interaction.

A correlation parameter - the jet penetration height - by which experimental results from different supersonic tests could be correlated, was formulated by Spaid. ${ }^{8}$ It is defined as the effective height of the external flow's disturbance caused by the jet, and is analogous to the height of an equivalent solid obstacle. Spaid's formulation of the penetration height of a circular under-expanded sonic jet into a planar supersonic flow ${ }^{8}$ required the following assumptions:

1) The penetration height is large compared with the boundary-layer thickness of the undisturbed flow.

2) The jet expands isentropically to the ambient pressure while being bent in the direction of the free flow.
3) The jet and the external klow do not mix.

4) The contact surface between the two flows is shaped like a quarter sphere attached to half of a cylindrical afterbody.

5) The pressure distribution over the spherical contace surface is calculable by Newtonian theory.

6) The jet penetration height, h, is equal to the radius of the quarter-sphere contact surface and its value can be determined by a momentum balance in the flow direction. The control volume for this momentum balance is delimited by the quarter sphere described above; the flat surface from which the jet is injected; and a plane perpendicular to the free flow, that passes through the rear of the quarter sphere.

Based on these assumptions, Spaid's momentum balance results in the penetration height given by

$$
\begin{aligned}
\frac{h}{d_{t}}= & \frac{1}{M_{\infty}}\left(\frac{2 C_{j}}{C_{p}^{*}} \frac{P_{0 j}}{P_{\infty}}\right)^{1 / 2}\left\{\frac{2}{\gamma_{j}-1}\left(\frac{2}{\gamma_{j}+1}\right)^{\gamma_{j}+1 / \gamma_{j}-1}\right. \\
& \left.\times\left[1-\left(\frac{P_{\infty}}{P_{o j}}\right)^{\gamma_{j}-1 / \gamma_{j}}\right]\right\}^{1 / 4}
\end{aligned}
$$

where $C_{p}^{\star}$ is the stagnation-pressure coefficient behind a normal shock wave.

$$
\begin{aligned}
C_{p}^{*}= & \frac{2}{\gamma_{\infty} M_{\infty}^{2}}\left[\left(\frac{\gamma_{\infty}+1}{2} M_{\infty}^{2}\right)^{\gamma_{\infty} / \gamma_{\infty}+1}\right. \\
& \left.\times\left(\frac{\gamma_{\infty}+1}{2 \gamma_{\infty} M_{\infty}^{2}-Y_{\infty}+1}\right)^{1 / \gamma_{\infty}-1}-1\right]
\end{aligned}
$$

The term $C_{p}^{*}$ was used by Spaid to calculate the drag on the quarter sphere by the Newtonian theory. An examination of Eq. (1) results in the approximate relationship

$$
h /\left(d_{t} C_{j}^{1 / 2}\right) \propto\left(1 / M_{\infty}\right)\left(p_{\circ j} / p_{\infty}\right)^{1 / 2}
$$

or, after rearranging:

$$
h \propto\left[\left(d_{t}^{2} C_{j} p_{0 j}\right) /\left(M_{\infty}^{2} P_{\infty}\right)\right]^{2 / 2}
$$

which means that the penetration height is proportional to the square root of the ratio of the jet thrust to the free-stream dynamic pressure. Other attempted correlations, like those of Refs. 9 and 10 , that were based on the jet-momentum flux (or thrust), also concluded that the interaction was governed by the ratio of the jet momentum to the specific momentum of the free flow.

While most of the research effort concentrated on supersonic interactions that were common in thrust-vectoring and direct-attitude control of missiles, very little work was done on transonic interactions. The scant available information (e.g., Fig. 3, taken from Ref. 11) shows that the transonic interaction is, generally speaking, similar in character to the previously described supersonic one. The main differences are that the pressure gradients are weaker, the pressure plateau 
is very short and vanishes at low injection pressure ratios, and the shock waves are weak normal shocks.

With the development of STOL Eighter aircraft and zuided and maneuvering munitions, the interest in cransonic inceractions increased. The present investigation was therefore concerned with the interaction of several circular supersonic jets with an external transonic flow that has hardly been studied before. A further difference from previous studies is that they dealt with injection from a Elat plate into a planar flow, whereas in this study a number of circular, radial jets are injected symmetrically from the perimeter of the base of an axisymmetrical body into a threedimensional outer flow. Thus, in the present case the jets do not generate any direct net forces or moments on the body. The forces and moments that were actuaily measured when the body was positioned in the flow at an angle of attack, were a result of small pressure differences between the interaction regions on the windward and leeward sides of the body.

The main purpose of this investigation was to gain a better insight into the jet interaction phenomena in transonic flow, and to evaluate the effects of the various flow and jet parameters on these phenomena. Results presented here show that the interaction generates additional lift and increases the longitudinal static stability at low angles of attack.

Most of the experiments were conducted with radial jets, but several tests were made with jets that were injected tangentially to the base circumference. Such jets could be used to generate high spin rates. No fundamental difference was observed between the results of the radial injection and the tangential injection, except for the rolling moments produced by the latter.

\section{Experimental Setup, Tests, and Data Reduction}

\section{Apparatus}

The experiments were conducted on an ogivecylinder configuration in the $50-$ by $80-\mathrm{cm}$ ventilated test section of the induction-driven, transonic, blowdown wind tunnel of the Aeronautical Research Center, Technion-Israel Institute of Technology (IIT).

A general view of the wind-tunnel model is given in Fig, 4. The 8-caliber, 45-m diam model had a 3-caliber ogive nose section and a 5-caliber cylindrical body. The base section of the model included the injection nozzle units (FIg. 5). Two interchangeable nozzle units were employed, one having radial nozzles and the other having tangential nozzles. All the nozzles were convergentdivergent supersonic nozzles. Seven out of the eight nozzles could be plugged for single-nozzle preliminary experiments. High-pressure air (pressures from $12 \mathrm{~atm}$ to $44 \mathrm{~atm}$ ) was supplied to the nozzles through a rigid sting support. The overall air mass flow was measured by a calibrated flow meter, and the result was validated by a calculation of the nozzle mass flux obtained from suitable pressure and temperature measurements and the nozzle-throat cross-section area. A schematic
Layout of the air-supply and Elow-measurement systems is shown in Fig. 6.

Seventy-seven pressure taps were drilled into the model, upstream of the nozzles. The arrangement of the pressure taps relative to the nozzles' plane is shown in Fig. 7. Most of the pressure caps were located on one side only of the model's pitch plane. Four pressure taps were located on the other side to validate the symmetry of the flow with respect to the angle-of-attack plane. The pressure taps were connected by 1 -mm (o.d.) stainless-steel tubes to pressure transducers. In the single-jet experiments, seven pressures on the generatrix leading to the nozzle were monitored continuously by seven separate pressure transducers, whereas in the eight-jet experiments the 77 pressures were scanned by two scanivalves. All the data were acquired and reduced by an NEFF 620/ Elliot CR-17 data-acquisition and computer system. Schlieren photographs of the interaction were also taken.

Tests

Single-Jet Tests. A series of preliminary wind-tunnel tests was conducted to yalidate the experimental apparatus and the data-reduction software. In these tests a single jet was injected from the nozzle on the upper generatrix $\left(\phi=0^{\circ}\right.$ in Fig. 7). Seven pressure taps along this generatrix were continuously monitored by individual pressure transducers. Seven single-jet tests were conducted at constant angles of attack of $\alpha=0^{\circ}$, $9^{\circ}$, and $-9^{\circ}$, with the Mach number varying continuously from 0.4 to 1.1 . The nominal injection pressure was $P_{o j}=40 \mathrm{~atm}$. The injection pressure ratio $\left(p_{o j} / p_{\infty}\right)$ varied between 44 and 89 , owing to the change in free-stream static pressure with increasing Mach number.

Multiple-Jet Tests. Thirty-seven data points were obtained with eight radial jets, and 13 data points were obtained with eight tangential jets. These data points were obtained for various combinations of the nominal values of the test parameters:

$$
\begin{aligned}
& \text { Angle of attack } \begin{aligned}
\alpha= & -5^{\circ}, 0^{\circ}, 5^{\circ}, 10^{\circ}, 15^{\circ},
\end{aligned} \\
& \text { Injection pressure ratios } P_{0 j} / P_{\infty}=20,40 \text {, } \\
& 60 \text { ro } 70
\end{aligned}
$$

Mach numbers $M_{\infty}=0.8,0.9,1.0$

\section{Data Reduction}

Aerodynamic Coefficients. In addition to the test parameters (including the jet mass flux), only pressure data on the model were recorded. Pressures were reduced to the conventional local pressure coefficients

$$
C_{p}=\left(p-p_{\infty}\right) /\left[1 / 2\left(Y_{\infty} P_{\infty} M_{\infty}^{2}\right)\right]
$$

The pressure distributions in the circumferential and axial directions were smoothed with third- and fourth-order polynomials. The smoothed pressure distributions were integrated to give the normal force coefficient $\left(\mathrm{C}_{N}\right)$ and the location of the center of pressure $\left(\mathrm{X}_{\mathrm{CP}} / \mathrm{D}\right)$ that was measured upstream of the injection plane. 


$$
\begin{aligned}
C_{N} & =-\frac{4}{4} \int_{0}^{2} \int_{0}^{\pi}\left[C_{p}(\phi, X / D) \cos \phi d \phi\right] d(X / D) \\
\left(X_{C P} / D\right) & =-\left[4 /\left(-C_{N}\right)\right] \int_{0}^{2} \int_{0}^{\pi}\left[C_{p}(\phi, X / D) \cos \rho d \theta\right]
\end{aligned}
$$

$<(X / D) d(X / D)$

The integration was performed over the two-diameter-long metric section only. The differences between the results obtained with third- and fourth-order smoothing were not significant.

Jet Penetration Height for Transonic Flow. Spaid's jet penetration height (h) was useful for correlating the pressure distributions obtained in different tests. ${ }^{3}$ For a similar correlation in the present work the jet penetration height must be rederined for transonic flow. For a single jet, Spaid's assumptions and formulation can be used, except for the drag coefficient on the quarterspherical face of the control surface. Instead of the drag being calculated by the Newtonian theory with the assumption of a strong normal bow shock upstream of the spherical surface, it is approximated in the transonic case by the empirical relation ${ }^{12}$

$$
C_{D}=C_{P_{O \infty}}-0.5 \text { (for } 0.7<M_{\infty}<1.2 \text { ) }
$$

where $C_{P_{0 \infty}}$ is the free-stream stagnation pressure coefficient. With this drag coefficient, the momentum balance results in

$$
\begin{aligned}
\frac{h}{d_{t}}= & \frac{1}{M_{\infty}}\left(\frac{C_{j}}{C_{P_{0 \infty}}-0.5} \frac{\gamma_{j}}{\gamma_{\infty}} \frac{P_{0 j}}{P_{\infty}}\right)^{1 / 2}\left\{\frac{2}{\gamma_{j}-1}\right. \\
& \left.\times\left(\frac{2}{\gamma_{j}+1}\right)^{1 / j^{+1 / \gamma_{j}-1}}\left[1-\left(\frac{P_{\infty}}{P_{o j}}\right)^{\gamma / 1 / \gamma_{j}}\right]\right\}^{1 / 4}-
\end{aligned}
$$

For experiments in cold flows (wind-tunnel and jet flows) with $\gamma_{j}=\gamma_{\infty}=1.4$, one derives from Eq.

$$
\begin{aligned}
\frac{h}{d_{t}\left(C_{j}\right)^{1 / 2}}= & \frac{1}{M_{\infty}}\left(\frac{1}{C_{P_{0 \infty}}-0.5} \frac{P_{0 j}}{P_{\infty}}\right)^{1 / 2} \\
& \times\left\{1.6745\left[1-\left(\frac{P_{\infty}}{P_{0 j}}\right)^{0.2857}\right]\right\}^{1 / 4}
\end{aligned}
$$

This formulation was derived for a single jet injected from a flat plate into a planar transonic flow. For the case of a jet injected from an axisymmetric body of diameter D, Eq. (9) would still be valid if $h / D \ll 1$. It is assumed that for higher values of $\mathrm{h} / \mathrm{D}$, Eq. (9) would still describe correctly the trends of the penetration height with varying jet and free-flow parameters. However, the derivation of the penetration height must be modified when multiple jets are injected radially from an axisymmetric body.

Using Spaid's assumptions, it is also assumed that the disturbance of a number ( $n$ ) of discrete circular jecs can be approximaced by a continuous, axisymetric radiat jet injected around the body perimeter, with a thrust that equals the combined thrust of the discrete jets. The momentum balance in this case is calculated for an annular control volume (Fig. 8) that is bounded by the spherical contact surface between 1) the tree flow and the jet, 2) the surface of the body, and 3) a radial plane that intersects the contact surtace at the point where the jet flow becomes parallel to the free stream. Rererring to Fig. 8, the momentum balance is given by:

$$
\dot{\mathrm{m}}_{j} V_{j}=1 / 2\left(\gamma_{\infty} P_{\infty} \mathrm{M}_{\infty}^{2} \mathrm{C}_{D}\right)(\pi / 4)\left[(D+2 h)^{2}-D^{2}\right]
$$

where $\dot{\mathrm{m}}_{j}$ is the combined mass flux of (n) jets

$$
\begin{aligned}
& \dot{\mathrm{m}}_{j}=c_{j} d_{j} P_{0 j}\left[\frac{\gamma_{j}}{R_{j} \tilde{I}_{o j}}\left(\frac{2}{\gamma_{j}+I}\right)^{\gamma_{j}+1 / \gamma_{j}-1}\right]^{1 / 2} \\
& A_{j}=n(\pi / 4) d_{t}^{2}
\end{aligned}
$$

and the jet exit velocity is

$$
v_{j}=\left\{\frac{2 \gamma_{j}}{\gamma_{j}-1} R_{j} T_{o j}\left[1-\left(\frac{P_{\infty}}{P_{o j}}\right)^{\gamma_{j}-1 / \gamma_{j}}\right]\right\}^{1 / 2}
$$

Substituting Eqs. (11) through (13) in Eq. (10) and using the empirical approximation for $C_{D}$ (Eq. (7)), the solution for the penetration height from Eq. (10) is :

$$
\begin{aligned}
h^{2}+D h= & {\left[\frac{C_{j} d_{t}^{2} n}{M_{\infty}^{2}\left(C_{P_{\infty \infty}}-0.5\right)}\right] \frac{P_{0 j}}{P_{\infty}}\left\{\frac{\gamma_{j}^{2}}{2\left(\gamma_{j}-1\right)}\right.} \\
& \left.\times\left(\frac{2}{\gamma_{j}+1}\right)^{\gamma_{j}+1 / \gamma_{j}^{-1}}\left[1-\left(\frac{P_{\infty}}{P_{o j}}\right)^{\gamma_{j}^{-1 / \gamma_{j}}}\right]\right\}^{1 / 2}
\end{aligned}
$$

The number of jets (n) must be high to justify the assumption of a continuous circumferential disturbance.

\section{Results and Discussion}

\section{$\underline{\text { Single-Jet Tests }}$}

Typical schlieren photographs of the interaction of a single jet with the transonic flow are shown in Figs. 9 and 10 . Figure 9 shows the effects of the jet on the boundary layer at angles of attack of $0^{\circ}$ and $9^{\circ}$. The thickening of the boundary layer due to the jet is not large. At $\alpha=9^{\circ}$ the boundary layer is separated some 1.5 body diameters upstream of the base, even without the jet disturbance. Figure 9 justifies the assumption that the jet penetration height is larger than the undisturbed boundary-layer thickness. As the free-stream Mach number is increased the jet is turned downstream closer to the body (Fig. 10), in spite of the increasing injection pressure ratio. The penetration height, calculated from Eq. (9), is also shown in Fig. 10. It does not correspond to any physical feature of the flow field and should be considered as a similarity parameter only. However, a qualitative agreement 
between the calculated penetration height and the jet radius of curvature is observed (Fig. 10).

The pressure distributions upstream of the jet (Fig. 11) are typical of transonic flow. The pressure increases gradually as the jet is approached. No pressure placeau is observed. Both the pressure levels and the upstream extent of the inceraction are increasing with increasing free-stream Mach number and injection pressure ratio. These two paramecers could not be varied independently in the blowdown tunnel because of the continuous variation of the Mach number in the single-jet tests. Note that the pressures are higher at both the positive and negative angles of attack $\left(\alpha= \pm 9^{\circ}\right)$ than at $\therefore=0^{\circ}$. This is an indication of the highly nonlinear character of the interaction (discussed later). The slightly higher pressures at the negative angle of attack $\left(\alpha=-9^{\circ}\right)$ than at the positive $\left(\alpha=9^{\circ}\right)$ predict the increased static stability that is later observed in the multiple-jet tests.

The single-jet data were compared, as a validation of the apparatus and data-reduction system, with the data of Ref. 6 . These data were normalized by an empirical penetration height

$\mathrm{h}_{\mathrm{c}} / \mathrm{d}_{t}=0.695\left(\mathrm{poj}_{\mathrm{j}} / \mathrm{p}_{\infty}\right)^{1 / 2}$ that was suggested by Ref. 13 as the distance from the nozzle to the Mach disk in a supersonic injection into a fluid at rest. The agreement (see Fig. 12) is rather good in spite of the jet in Ref. 6 being injected from the ogivecylinder junction and not at the base, as on the present model.

\section{Multiple-Jet Tests}

Typical pressure distributions with eight active jets at $M_{\infty}=0.9$ and $p_{0 j} / p_{\infty}=65$ to 67 are presented in Figs. 13 and 14 for $\alpha=0^{\circ}$ and $x=10.1^{\circ}$, respectively. At $x=0^{\circ}$ (Fig. 13) the flow is nearly axisymetric. The only deviations from an axisymmetric flow are measured very close to the injection nozzles. High pressures are observed in line with the nozzle and lower pressures are observed between the nozzles. The pressure gradually increases as the nozzles are approached, except at the pressure taps between the nozzles in the last 0.2 body diameters. At $\alpha=10.1^{\circ}$ the effect of the crossflow can be seen, in addition to that of a stronger interaction between the jets and the outer flow (Fig. 14). One can observe (as in Eig. 11) that the pressures on the windward side are ilightly higher than those on the leeward side. The results shown in Figs. 13 and 14 are characteristic and are shown as an example. Additional pressure distributions, obtained for different test conditions, are presented in Ref. 14.

The variation of the normal force coefficient with the angle of attack is shown in Fig. 15 for various Mach numbers and injection pressure ratios. Also shown in Fig. 15 are the conventional normal force results without injection. These compare very well with the predictions of the crossflow theory, 15 except for the experimentally observed increase with increasing Mach number. The normal force induced by the interaction of the jets with the outer flow is larger than that induced by the crossflow alone (Fig. 15), especially at the lower angles of attack $\left(0^{\circ}<a<5^{\circ}\right)$. These jet-induced normal-force increments diminish at the higher angles of attack. The apparent scatter in the data in Fig. 15 could be due to the simultaneous variation of the Mach number and infection pressure ratio. The data are therefore replotted in Fig. 16 as a Eunction of the injection pressure ratio for various Mach numbers and angles or attack. When one takes into account the angle-of-attack effects (of Fig. 15), only a weak influence of the injection pressure ratio on the normal force is found (for $20 \leq p_{0 j} / p_{\infty} \leq 70$ ). Most of the apparent scatter in Eig. 15 must, therefore, be a Mach number effect, with the normal force increasing when the Mach number is increased (for $0.8 \leq M_{\infty} \leq 1.02$ ).

The downstream displacement of the center-ofpressure location (o $\vec{r}$ the metric section of the model only), caused by the jet-induced interaction, is shown in Fig. 17 as a function of the angle of attack for various Mach numbers and injection pressure ratios. This displacement is largest around $i=5^{\circ}$ and decreases rapidly as the angle of attack is increased. The effect of the interaction, like its influence on the normal force (Fig. 15), seems to vanish for $\alpha>20^{\circ}$ where the crossflow apparently dominates the flow field, and the jet-induced interaction becomes insignificant. When the center-of-pressure data are replotted as a function of the injection pressure ratio

(Fig. 18), it is found that the downstream displacement of the center of pressure increases when the infection pressure ratio is increased. The Mach number effect on this phenomenon seems to be sma11.

Although the dependence of the normal force (the integral of the pressure distribution, Eq. (5)) on the injection pressure ratio is quite weak (Fig. 16), its effects on the pressure distribution itself are significant (Figs. 19a and 19c). This interesting result indicates that the pressure distribution only shifts while it maintains a constant average. This shifting is reflected in the aft movement of the center of pressure with increasing injection pressure ratio (Fig. 18). The effects of the injection pressure ratio on the pressure distribution can be correlated with the penetration height as given by Eq. (14) (Figs. 19b and 19d). However, there still remains the effect of the angle of attack because, strictly speaking, the derivation of the penetration height is valid only for $\alpha=0^{\circ}$. Even so, the correlation in Fig. 19b that includes data at $\alpha=0^{\circ}$ and $5^{\circ}$, and in Fig. 19d at $\alpha=10^{\circ}$, is quite good.

The pressure distriburions obtained with a single jet and with eight jets are compared in Fig. 20 at approximately identical test conditions. The pressure field induced by the eight jets is much stronger and has a much more extensive influence (more than double) than the single-jet pressure field. An attempt was made to scale the streamwise distance (X/D) with the jet penetration heights for these two cases. This brought the two curves closer together (not shown) but did not correlate them, since the ratio of the eight-jet to the single-jet penetration heights was only z1.3. The different character of the eight-jet interaction can also be seen when comparing its schlieren photographs (Fig. 21) with the single-jet photographs (Fig. 10). The penetration height (Eq. (14)) is marked on these photographs (Fig. 21) and, again as in Fig. 10, shows the same trend as the radius of curvature of the jet.

A better understanding of the behavior of the normal force (Fig. 15) can be obtained from a 
arossplot of the streamwise pressure distriburions at various angles of attack. Figure 22 shows the variation of the pressures with the angle of attack at fixed axial stations along the upper generatrix ahead of the jet for constant nominal test conditions. Also shown for comparison is the pressure variation with the angle of atcack without blowing, which does not change with $X / D$ on this section of the nodel. The interaction field can be roughly divided into two regions of different character. The first is the far-upstream region $(\mathrm{X} / \mathrm{D}>0.5)$. There, the pressure variation generally resembles the crosstilow-induced variation without injection. The pressure levels are, of course, higher than without injection, and increasing in the downstream direction because of the Eree-flow retardation by the jets' obstacle. In the near region $(\mathrm{X} / \mathrm{D}<0.5)$ the jet disturbance is the dominant factor and the pressure variation differs significantly from the crossilow type. The pressure variation with the angle of attack is highly nonlinear and has a sharp minimum in the vicinity of $\alpha \cong 5^{\circ}$. This minimum is the reason for the very rapid increase in the contribution of the interaction pressure field to the normal force when the angle of attack is increased from $0^{\circ}$ to $5^{\circ}$ (Fig. 15), and for its diminishing at higher angles of attack. It also explains why the pressures in Fig. 11 for both $\alpha=9^{\circ}$ and $\alpha=-9^{\circ}$ were higher than those at $\alpha=0^{\circ}$.

Another interesting result (Fig. 23) is the normal force distribution along the body (at $M_{\infty}=0.9$ and $x=10^{\circ}$ ) for several injection pressure ratios (including $p_{o j} / p_{\infty}=0$ ). The increasing pressure ratio increases the pressure loading on a body section near the jets of about 1-diam length but reduces the load farther upstream, with even some locally negative lift at the highest injection pressure. The overall result of this change in the distribution is that the total normal force (the integral under the curves in Fig. 23) changes very little with varying pressure ratio (for $20 \leq p_{0 j} / p_{\infty} \leq 70$, as in Fig. 16) compared with the pressure distribution itself (Figs. 19a and $19 c)$, so that the center of pressure moves aft, closer to the jets (also in Fig. 18). When similar normal-force distribution curves, all with the same injection pressure ratio, are plotted for several angles of attack (Fig. 24), the influence of the angle of attack is not monotonous, as was that of the injection pressure. The interaction contributes significantly to the normal force at low angles of attack $\left(\alpha<10^{\circ}\right)$, with the maximum contribution in the vicinity of $\approx \cong 5^{\circ}$. At higher angles of attack this contribution diminishes very rapidly and the normal force is increasingly governed by the crossflow mechanism. At $x=18^{\circ}$ (the maximum angle of attack considered in these tests), the jet interaction contributed only $15 \%$ of the total normal force acting on the cylindrical segment upstream of the jets, whereas at $\alpha=5^{\circ}$ the interaction contributed about $85 \%$ of the total normal force. Similar results can also be seen in Fig. 15.

\section{Tangential Injection}

The tests with the tangential jets were considered necessary because it seemed that for identical test conditions the disturbance to the outer flow (or the equivalent solid obstacle) presented by tangential jets should be smaller than that of radial jets. This expectation turned out to be incorrect. Typical pressure distributions at $x \cong 0^{\circ}$ and $5^{\circ}$ are compared with the corresponding pressure distributions obtained with radial jets (Figs. 25a and 25b, respectively) and are found to be very much alike, except for small differences in the region near the jets. It is not surprising, therefore, that the normal force and center of pressure dependence on Mach number, injection pressure ratio, and angle of attack is also similar co that of the radial-jet case (Figs. 25c and 25d). The differences between the results of the two modes of injection are within the scatter of the experimental data.

\section{Equivalent Flare}

An interaction between a transonic flow and transverse supersonic jets has never been solved numerically and the effort required for such a computation vould probably not be cost effective. However, the following crude approximation can be used for engineering design purposes. Both the schlieren picture (Fig. 21) and the pressure distributions (Fig. 13) of the eight-jet-induced flow field resemble those abtained on flared-cylinder models. Although the obstacle that is presented to the flow by the jets is not conical, an effective conical flare can be found that will produce the same approximate normal force and center of pressure. Since the jet-induced disturbance is distorted at higher angles of attack, such an approximation is valid at low angles of attack only. A conical Elare of $5.7^{\circ}$ semivertex angle would produce the results presented in Figs. 26 and 27 for $0 \leq y \leq 5^{\circ}$. A linear variation between the flare-induced values and those of the crossflow theory is proposed for use in the angleof-attack range between $a=5^{\circ}$ and $20^{\circ}$.

\section{Conclusions}

The interaction of a transonic free flow with eight circular jets, injected into the flow around the perimeter of the base of an axisymetric body, was studied experimentally. Radial and tangential injection modes were investigated. A jet penetration height for transonic flow was derived. This parameter correlates the pressure distributions, obtained with different injection pressure ratios at the same Mach number and angle of attack, on a single curve.

The pressure field induced on the section of the body upstream of the jets contributes a net positive normal force and moves the longitudinal center of pressure aft when the blowing is turned on at $P_{o j} / P_{\infty}=20$. The normal force is relatively insensitive to changes in the injection pressure ratio, (within the range $20 \leq \mathrm{poj}_{\mathrm{j}} / \mathrm{p}_{\infty} \leq 70$ ). However, the pressure distribution does change, so that the center of pressure moves farther aft toward the jets with 1ncreasing pressure ratio.

The dependence of the pressure field and the normal force on the angle of attack is highly nonlinear. This is apparently a result of flow separation from the leeward side of the body at angles of attack larger than $5^{\circ}$. The largest contribution of the interaction to the normal force occurs in the vicinity of $\alpha \cong 5^{\circ}$ and diminishes rapidly when the angle of attack is increased. The crossflow mechanism dominates the flow field for higher angles of attack, apparently resulting from the 
existence of separated Elow above the upper surface of the body.

No significant differences between the results of radial injection and tangential injection were found.

Simple approximations of the normal-force and center-oi-pressure variacions with angle of artack, based on an equivalent cylinder flare model, can be used for engineering design purposes.

\section{References}

-Spaid, F. W. and Zukoski, E. E., "A Study of the Interaction of Gaseous Jets from Transverse Slots with Supersonic External Flows," AIAA Journal, Vol. 6, Feb. 1968, pp. 205-212.

${ }^{2}$ Hsia, H. T. S., "Equivalence of Secondary Injection to a Blunt Body in Supersonic Flow," AIAA Journal, Vol. 4, Oct. 1966, pp. 1832-1834.

${ }^{3}$ Billig, F. S., Orth, R. C., and Laskey, M. A., "Unified Analysis of Gaseous Jets Penetration," AIAA Journal, Vol. 9, June 1971, pp. 1048-1058.

${ }^{4}$ Kallis, J. M., "Equivalent Solid Obstacle for Gas Injection into a Supersonic Stream," AIAA Journal, Vol. 10, Oct. 1972, pp. 1342-1344.

${ }^{5}$ Spaid, F. W., Zukoski, E. E., and Rosen, R., "A Study of Secondary Injection of Gases into a Supersonic Flow," NASA TR-32-834, Jet Propulsion Laboratory, Pasadena, Calif., 1966.

${ }^{6}$ Spaid, F. W. and Cassel, L. A., "Aerodynamic Interference Induced by Reaction Controls," AGARD $A G-173(A D-775209), 1973$.

${ }^{7}$ Chrans, L. J. and Collins, D. J., "Stagnation Temperature and Molecular Weight Effects in Jet Penetration," AIAA Journal, Vol. 8, Feb. 1970, pp. 287-293.
${ }^{3}$ Spaid, E. W., "A Study ot Secondary Injection of Gases into a Supersonic Flow," Ph.D. Thesis, California Institure of Technology, Pasadena, Calif., 1964.

${ }^{3}$ Hawk, H. E. and Amick, J. L., "TwoDimensional Secondary Jet Interaction with a Supersonic Stream," IIAA Journal, Vo1. 5, April 1967 , pp. $650-655$.

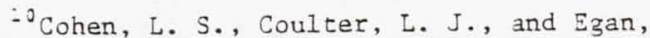
W. J., Jr., "Penetration and Mixing of Multiple Gas Jets Subjected to a Cross Elow," AIAA Journa1, Vol. 9, April 1971, pp. 718-724.

-Heyser, A. and Maurer, F., "Experimentalle Untersuchungen an festen Spoilern und StrahIspoilern bei Machschen Zahlen von 0.6 bis 2.8," $Z$. Flugwiss., Vol. 10, 1962, Hert $4 / 5$.

${ }^{12}$ Shapiro, A. H., The Dynamics and Thermodynamics of Compressible Fluid Flow, Vol. I, The Roland Press Co., New York, 1953, p. 410.

${ }^{13}$ Crist, S., Sherman, P. M., and Glass, D. R., "Study of the Highly Under-Expanded Sonic Jet," AIAA Journal, Vol. 4, Jan. 1966, pp. 68-71.

$1^{4}$ Manela, J., "The Influence of Jets, Injected Transversely into a Transonic Flow Near the Base of an Axisymmetric Configuration, on Flow Field, Lift and Stabilfty Characteristics of the Body," M.Sc. Thesis, Technion-Israel Institute of Technology, Haifa, Israel, Nov. 1980.

15 Jorgensen, L. H., "Prediction of Static Aerodynamic Characteristics for Slender Bodies Alone and With Lifting Surfaces at Very High Angles of Attack," NASA TMX-M3123, July 1976.

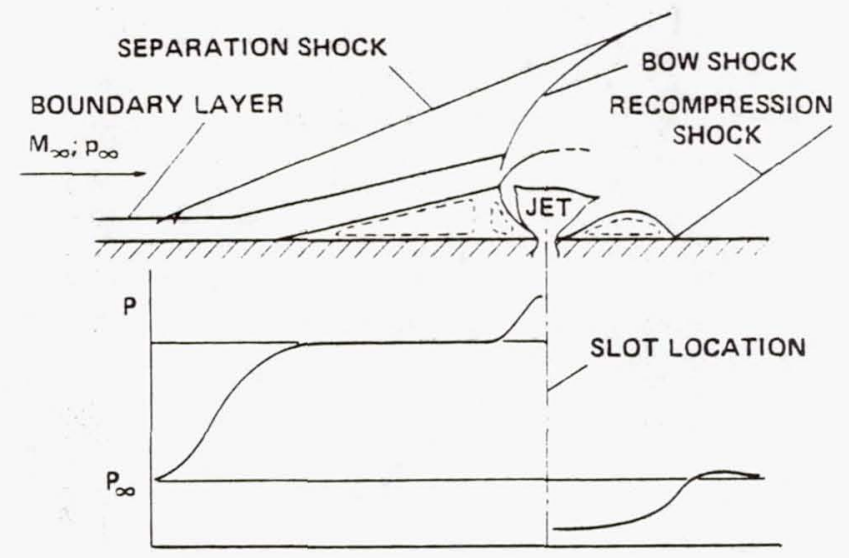

Fig. 1 Flow field and pressure distribution of a supersonic flow over a two-dimensional jet (from Ref. 1). 


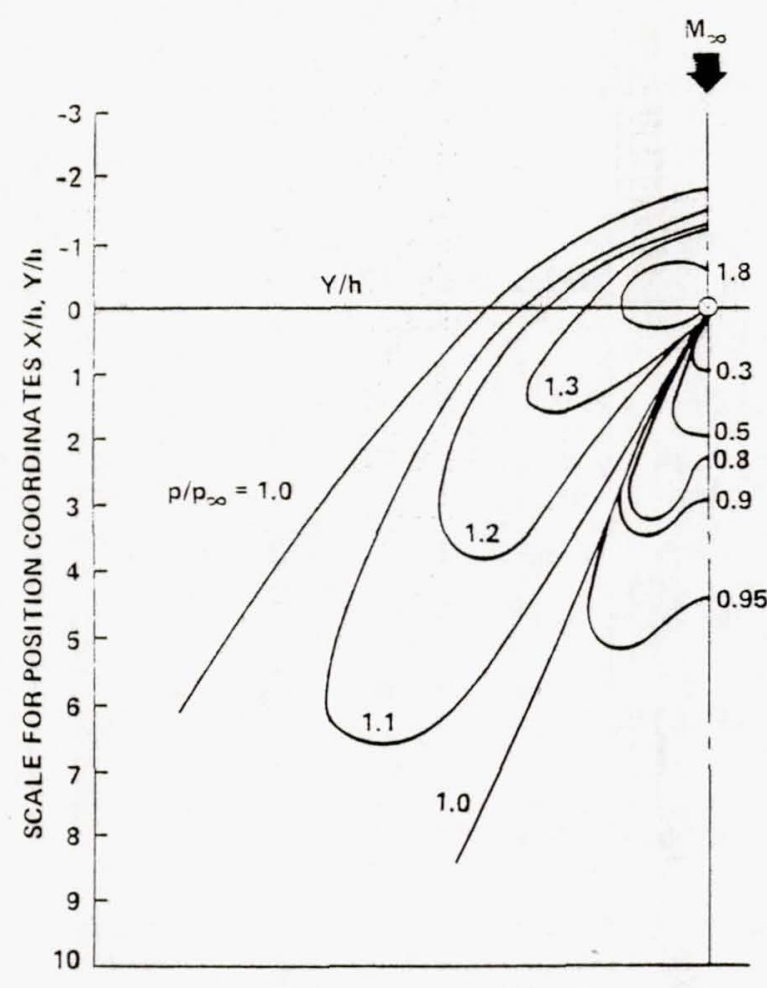

a) SINGLE JET

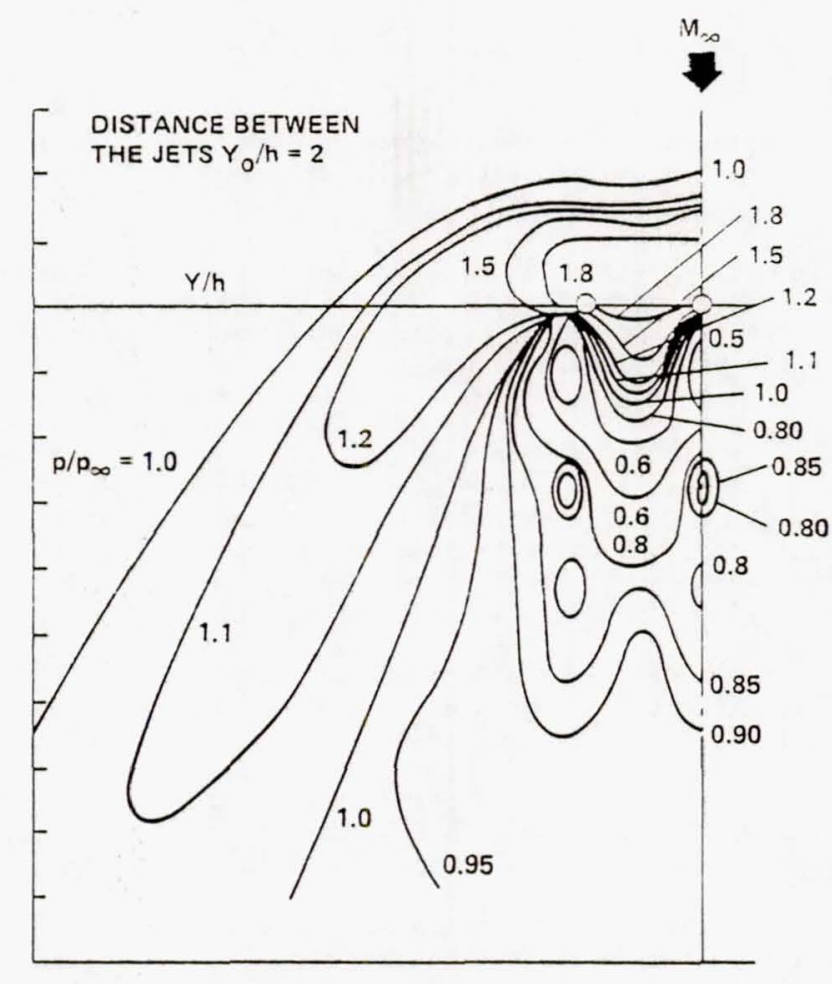

b) TWO ADJACENT JETS

Fig. 2 Typical pressure distributions around a circular jet interacting with a supersonic flow.

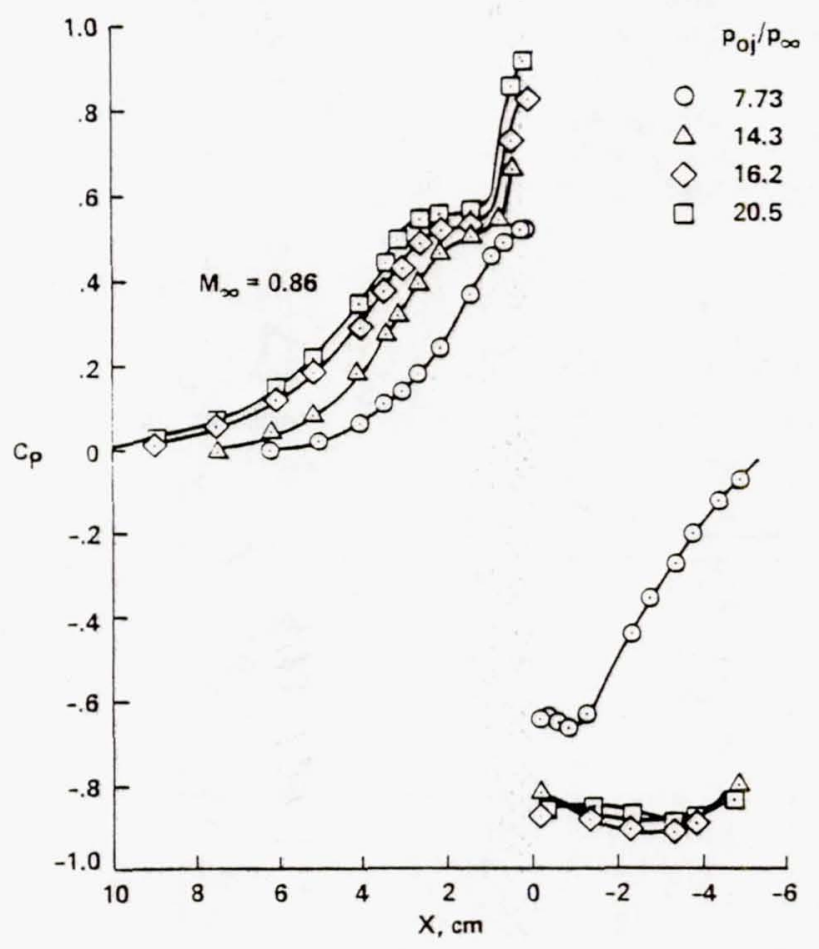

Fig. 3 Typical pressure distributions in a transonic interaction. 

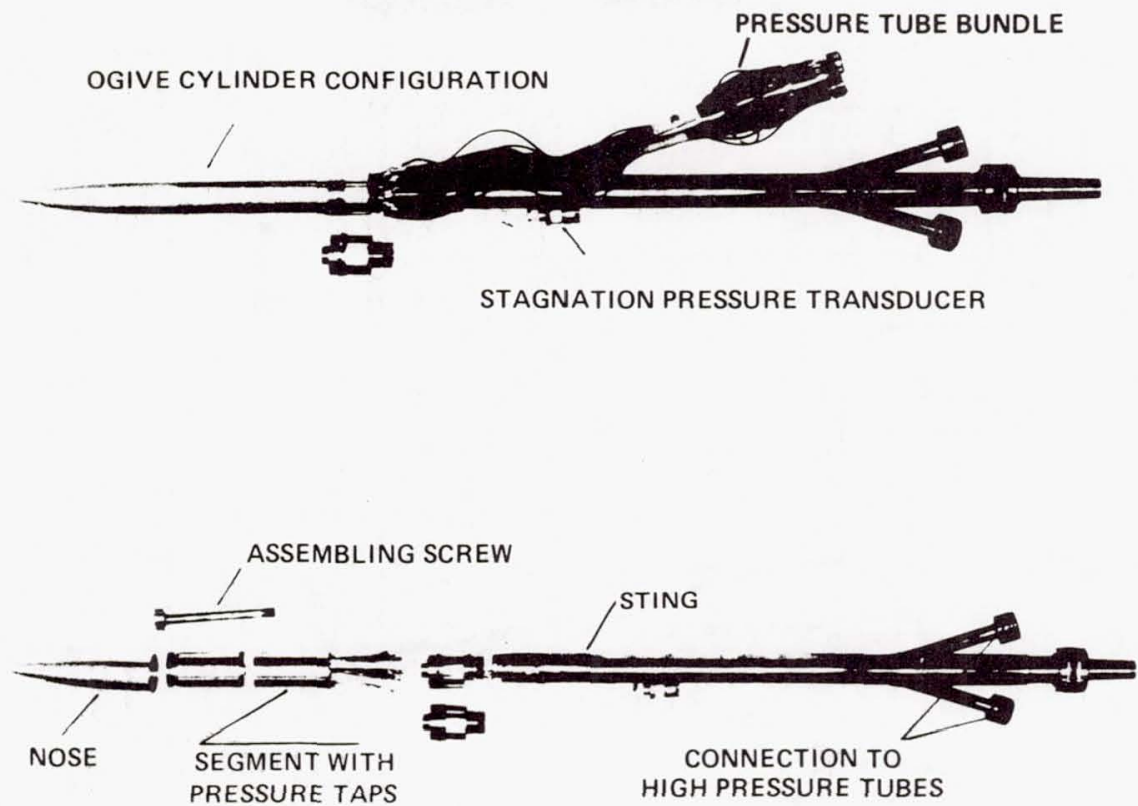

Fig. 4 General view of the wind-tunnel model.

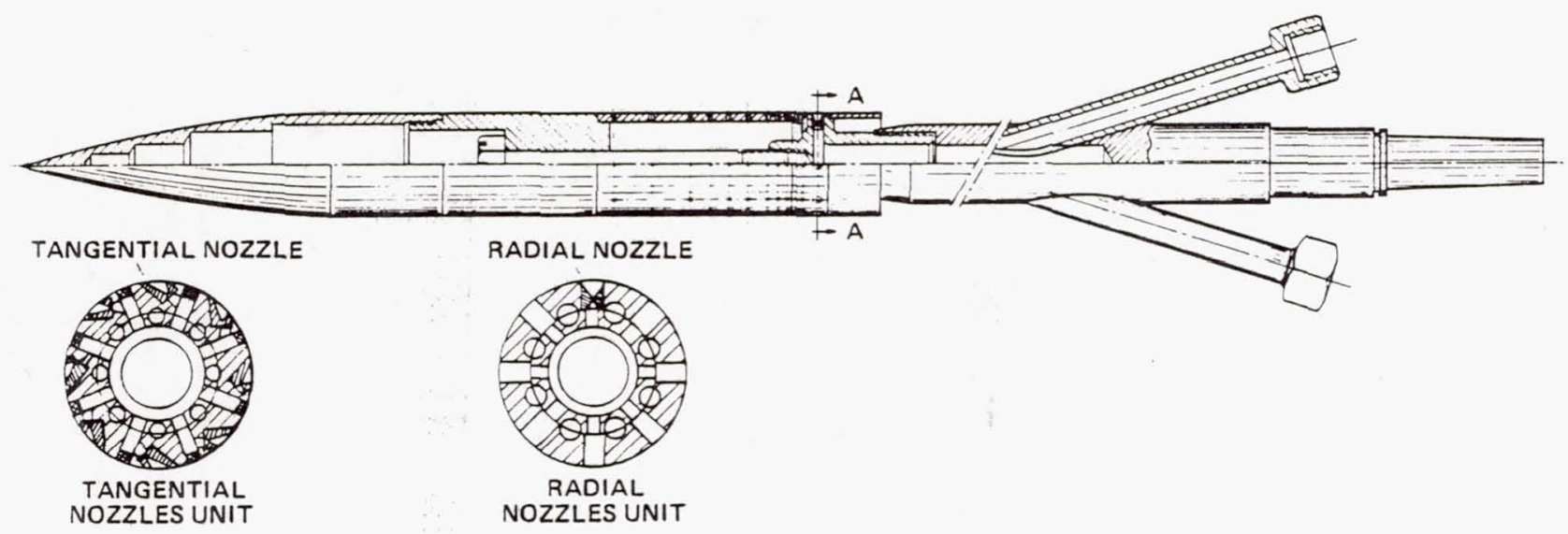

Fig. 5 Details of the wind-tunnel model. 


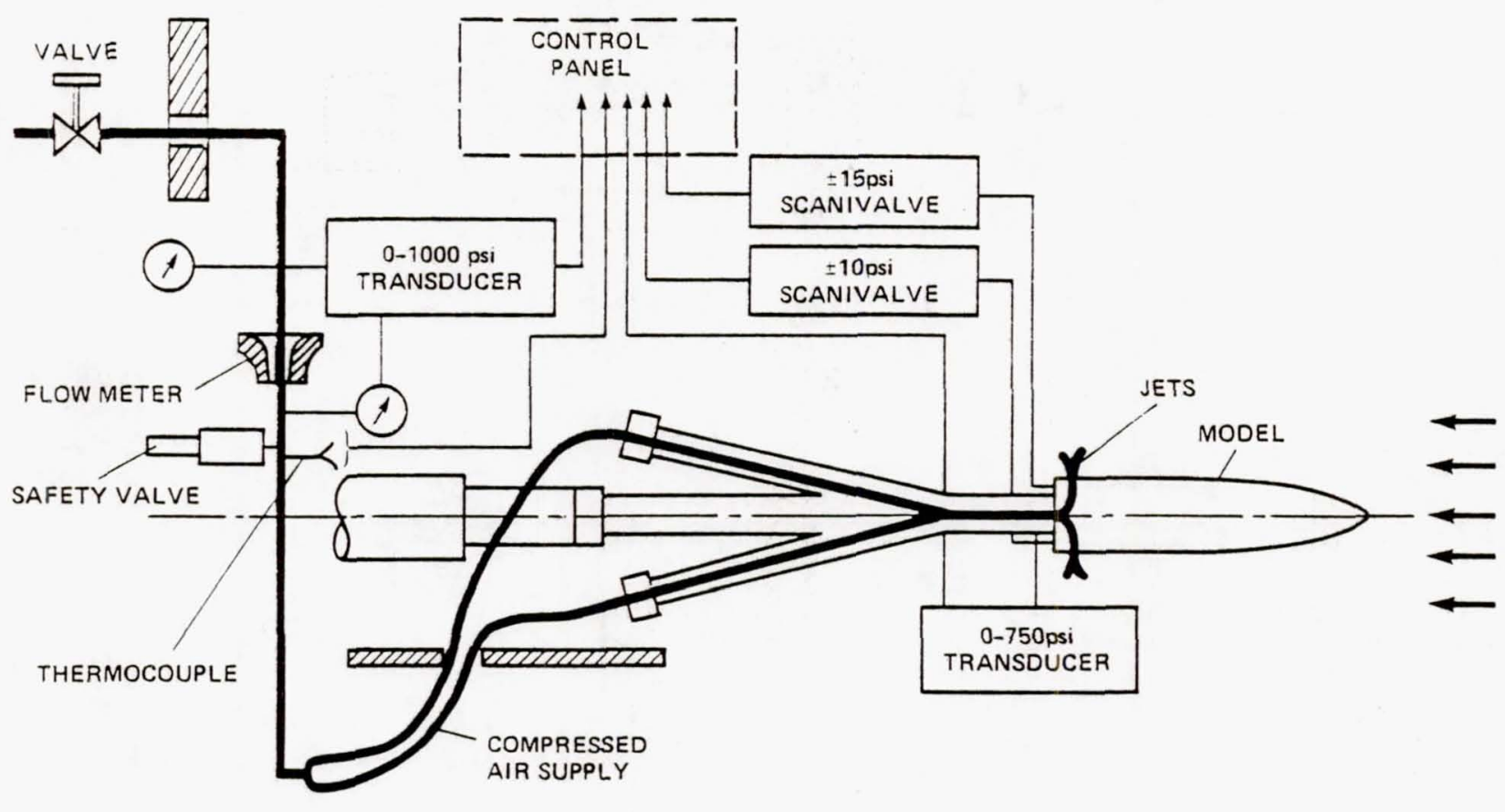

Fig. 6 Schematic layout of the test apparatus. 

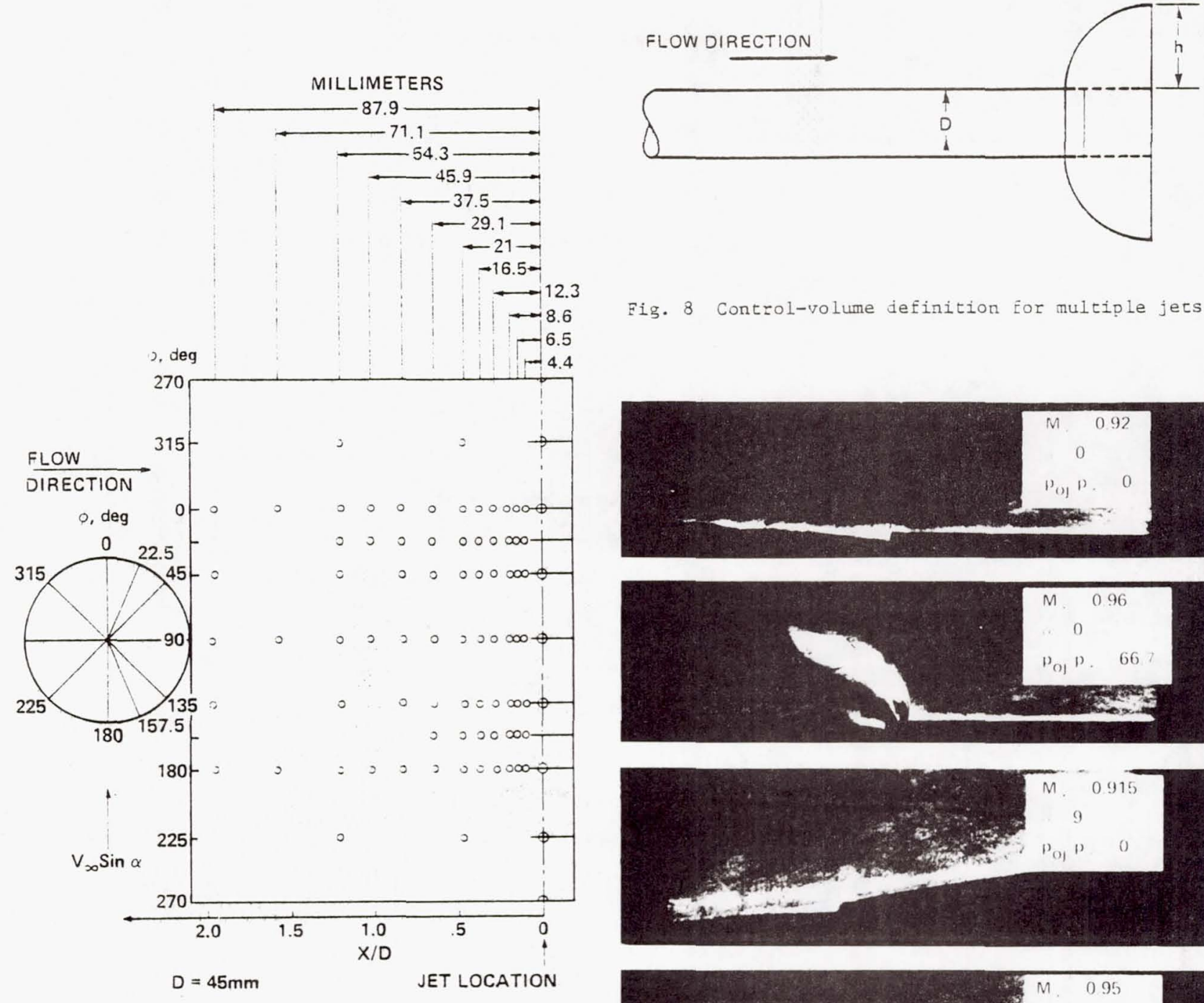

Fig. 8 Control-volume definition for multiple jets.
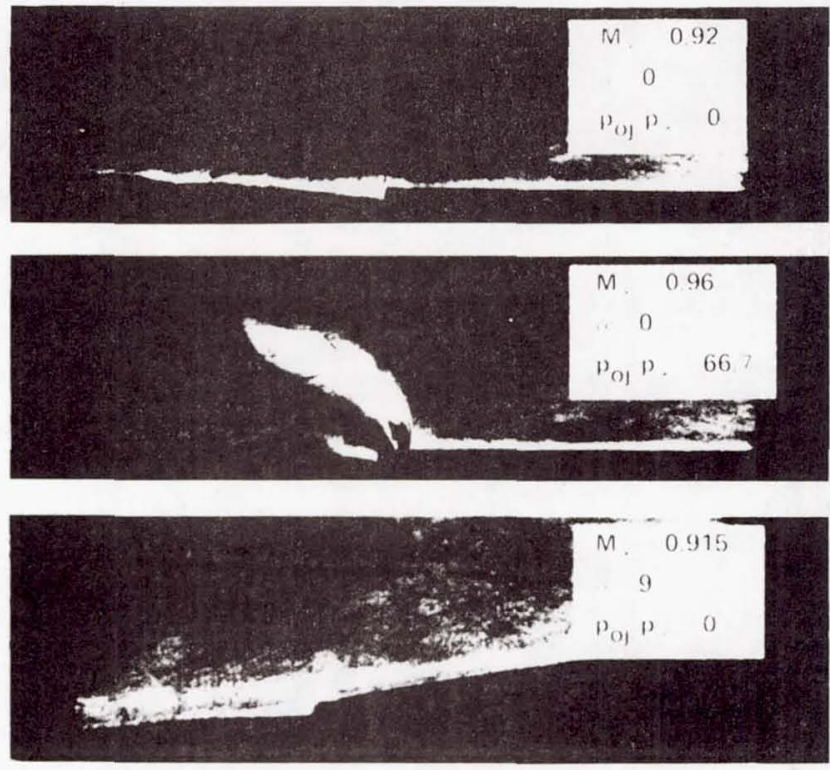

Eig. 7 Pressure tap arrangement.

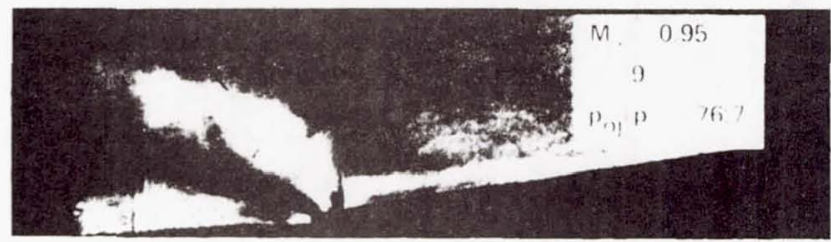

Fig. 9 jingle-jet influence on the boundary layer. 

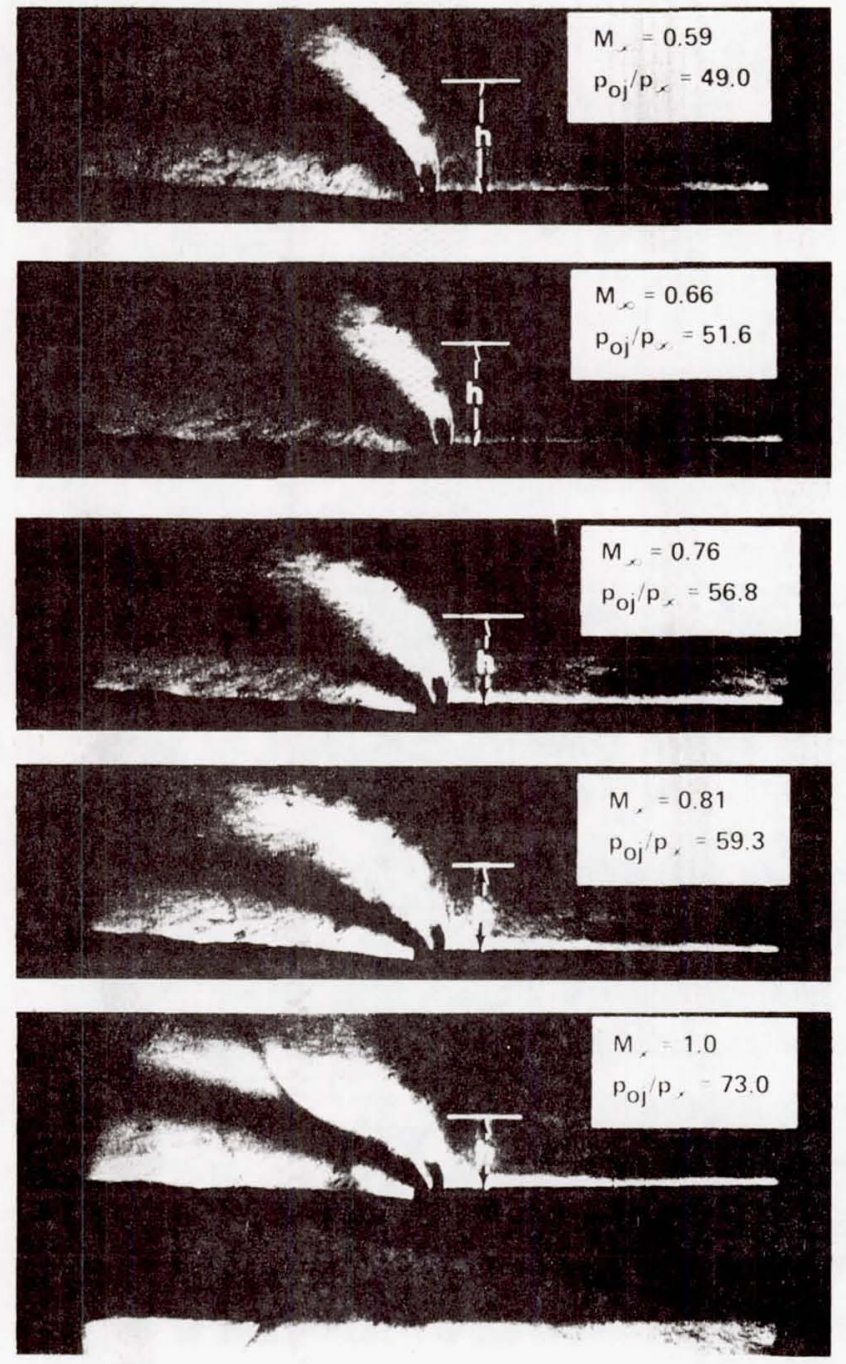

Eig. 10 Mach-number and pressure-ratio effects on a single-jet penetration.

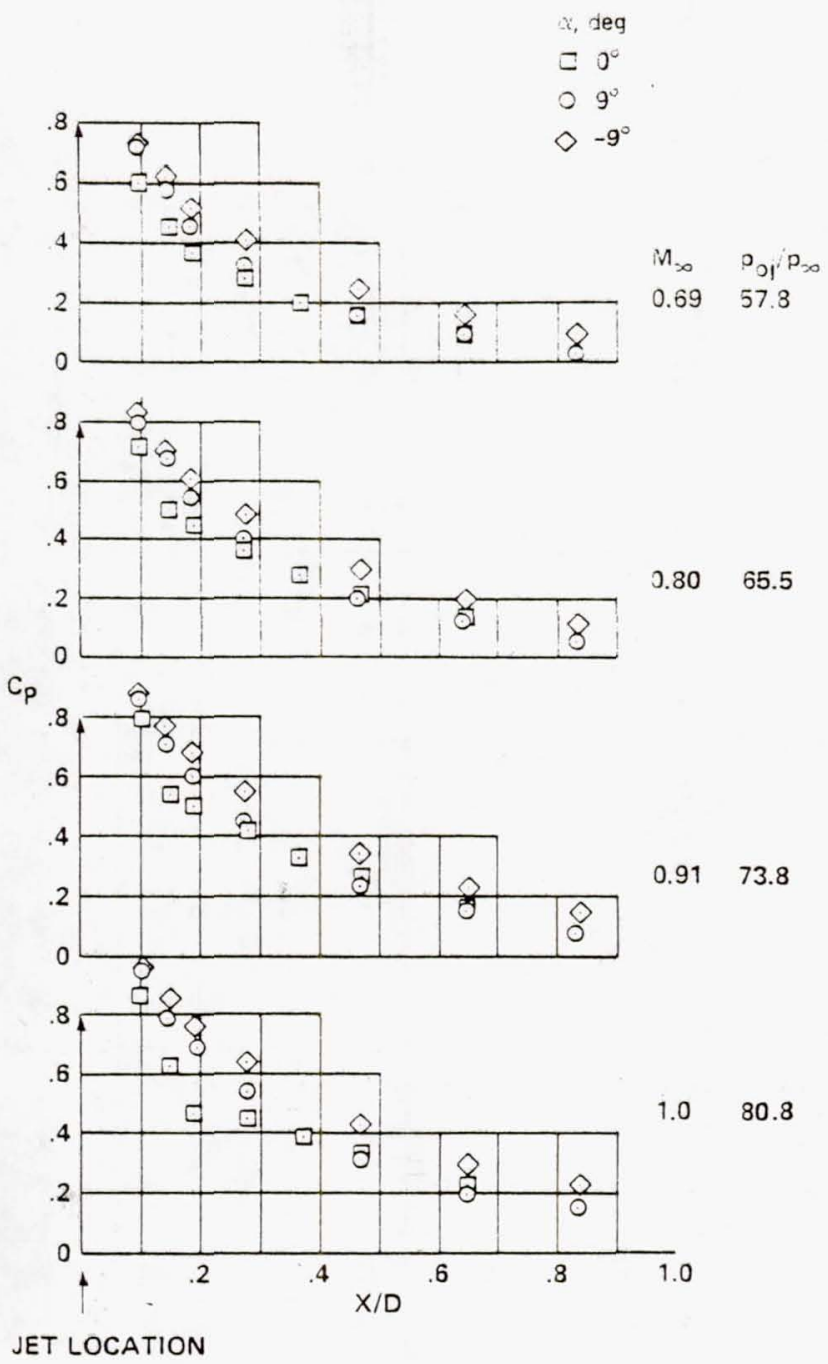

Fig. 11 Single-jet pressure distributions. 


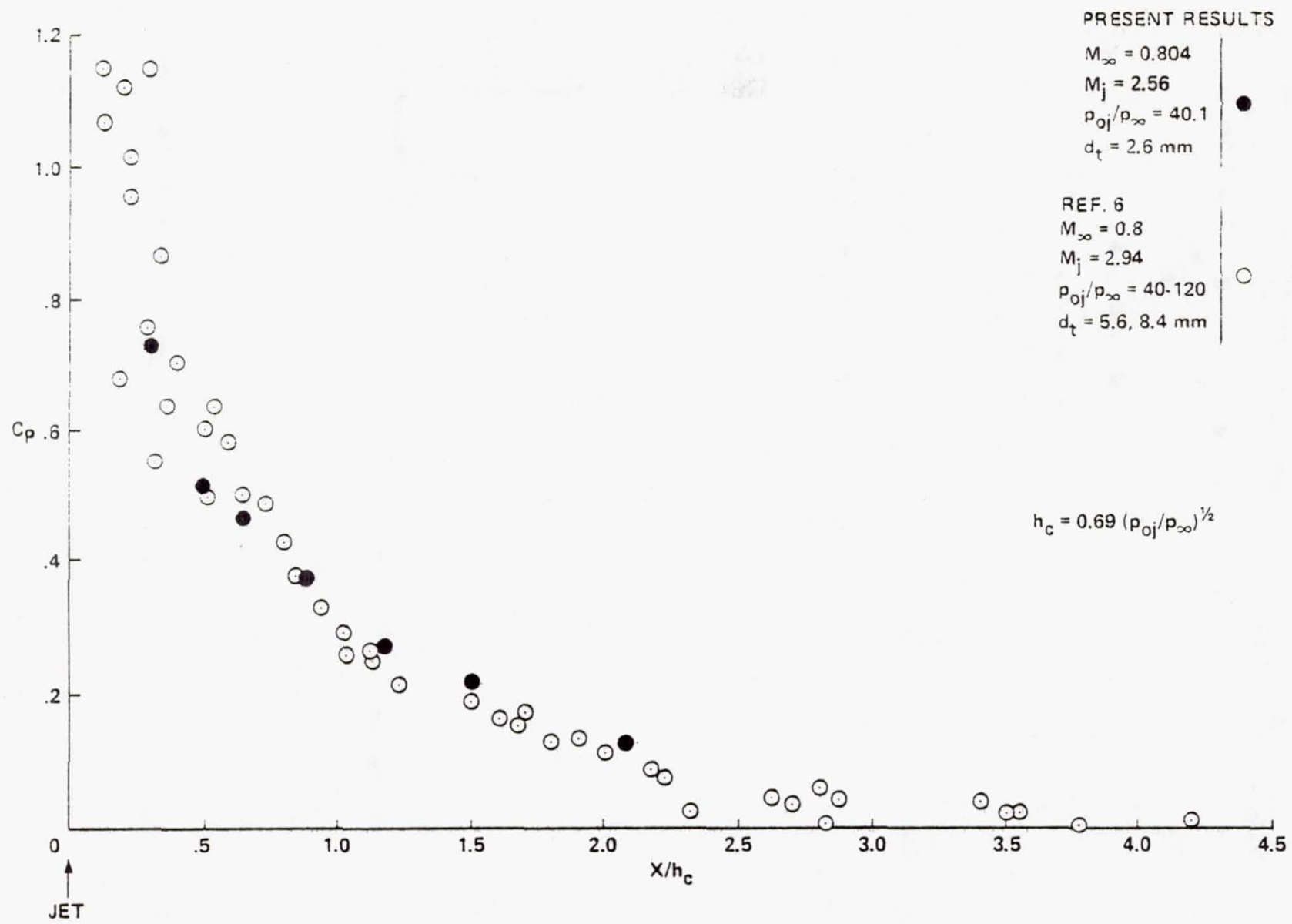

Fig. 12 Single-jet results compared with data from Ref. 6.

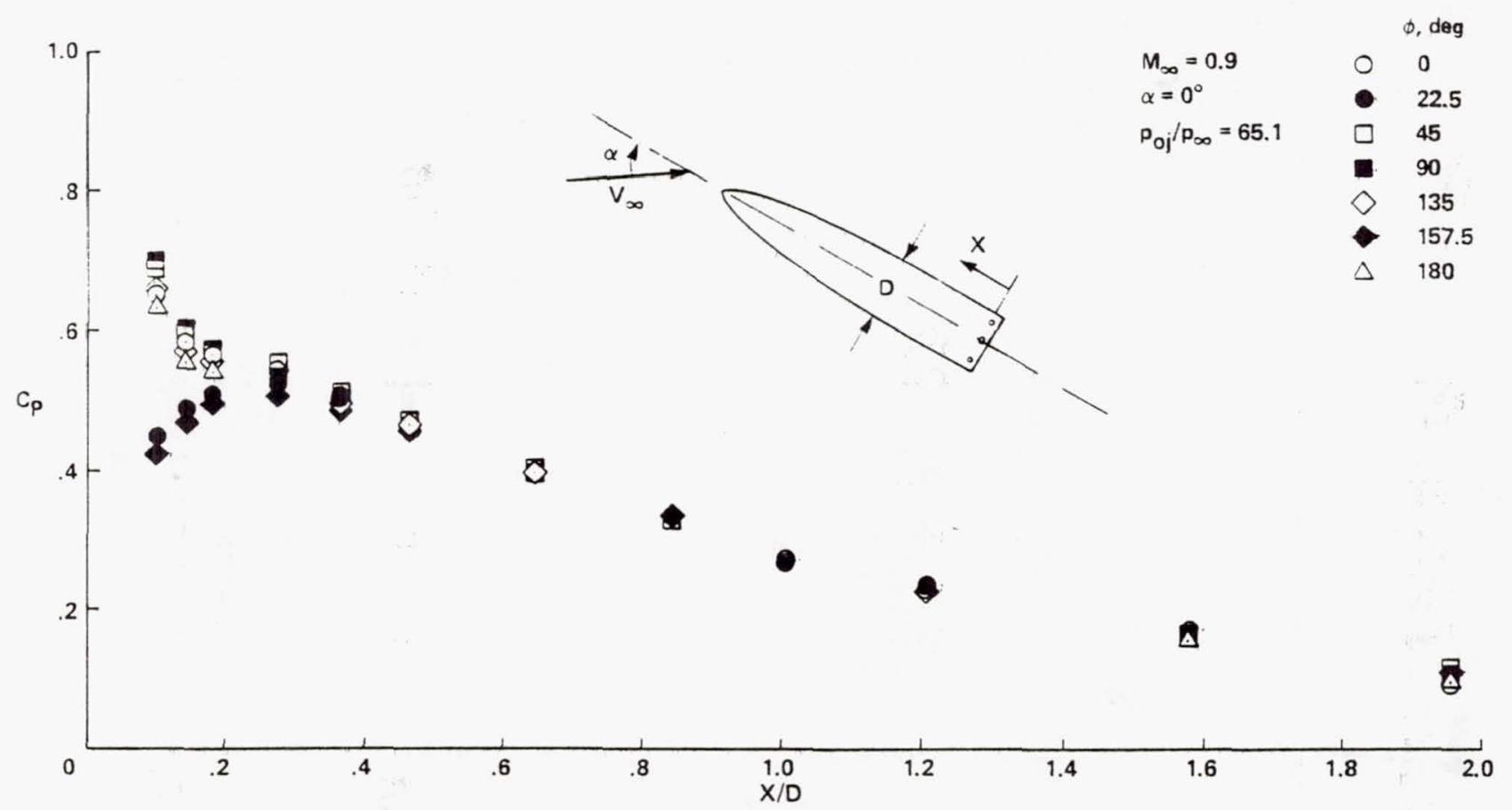

Fig. 13 Pressure distribution at $\alpha=0^{\circ}$ for eight radial jets. 


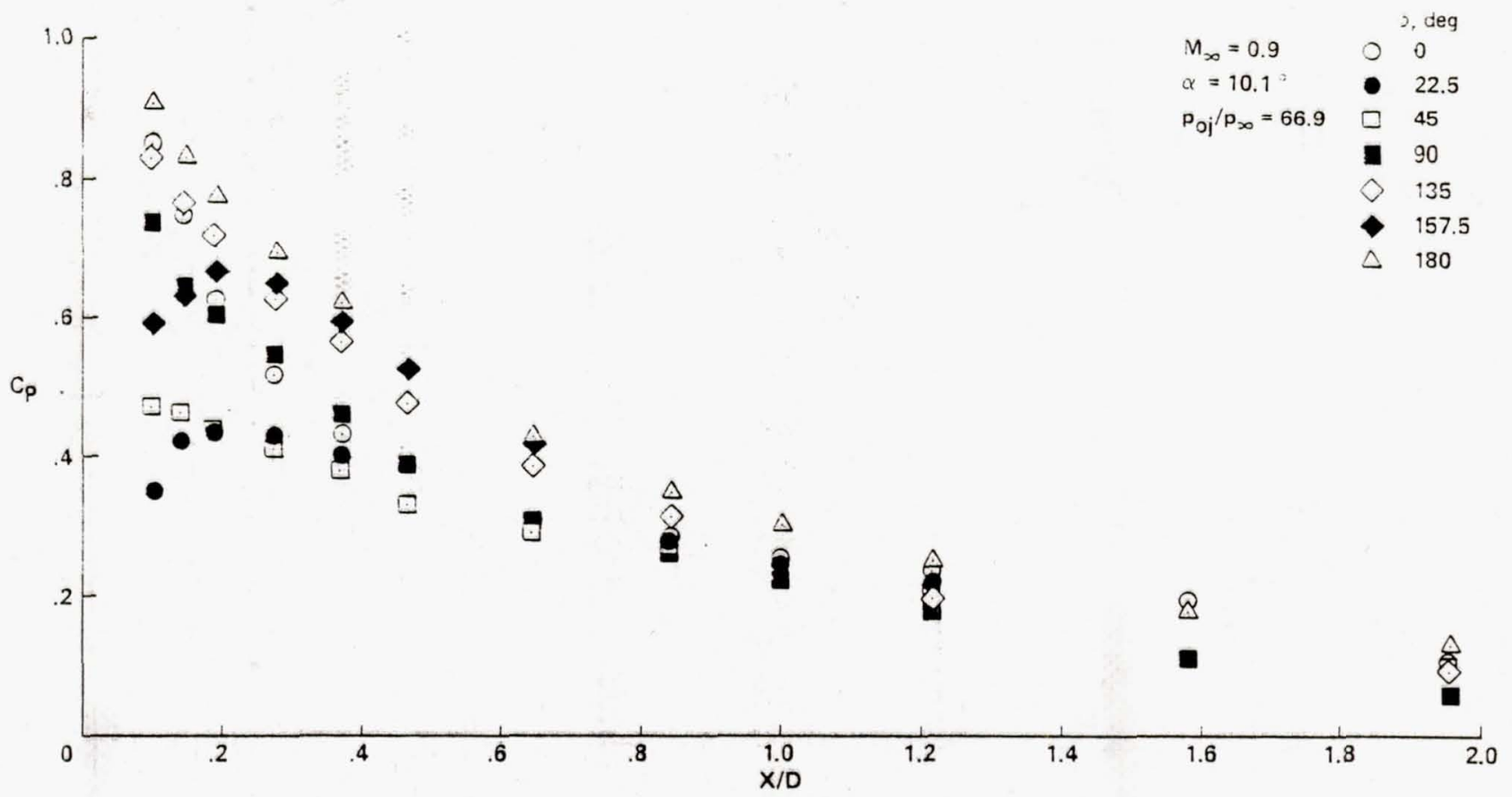

F1g. 14 Pressure distribution at $\alpha=10.1^{\circ}$ for eight radial jets.

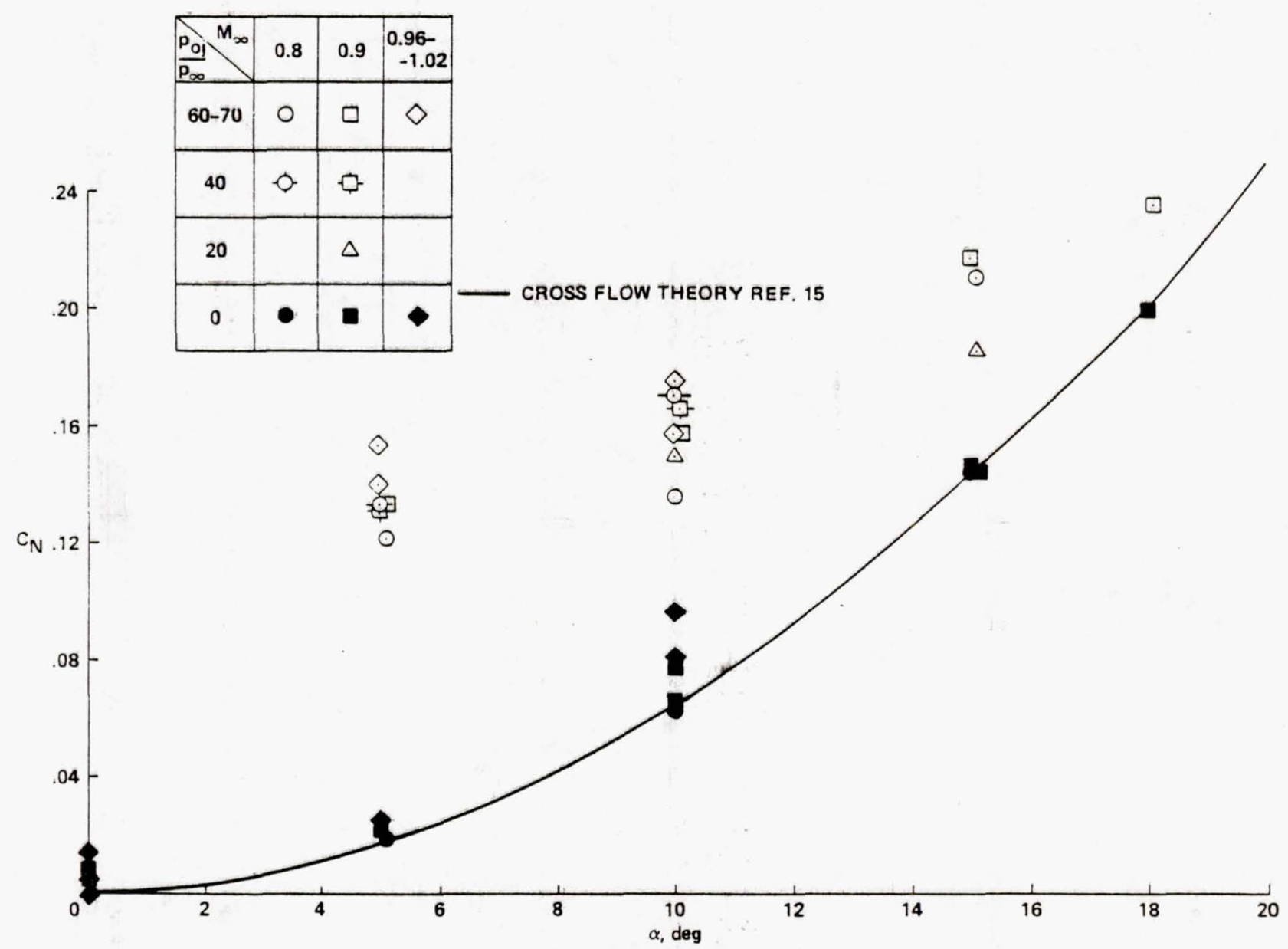

Fig. 15 Normal-force coefficient variations with angle of attack. 


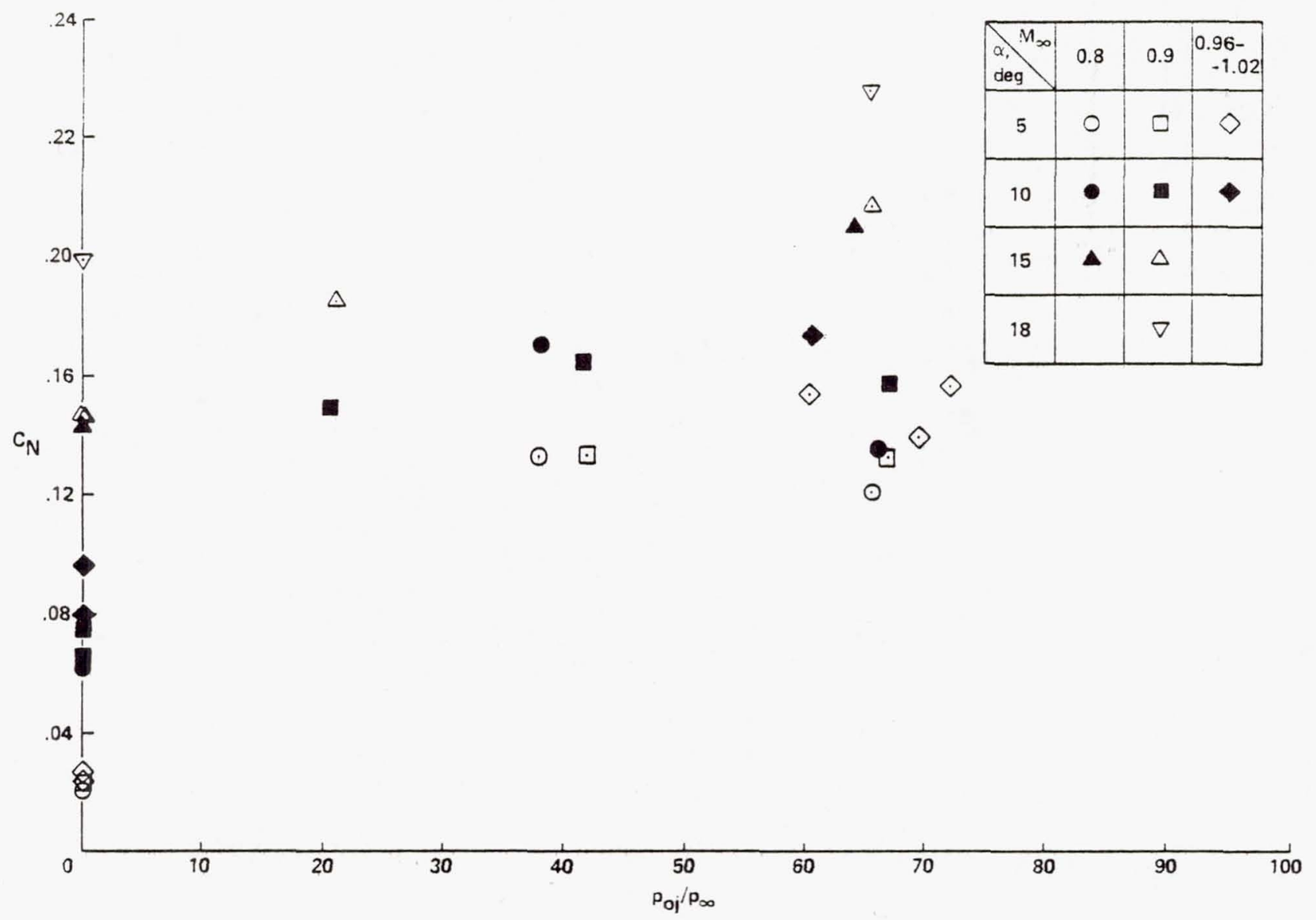

Fig. 16 Pressure-ratio effects on the nomal-force coefficient. 


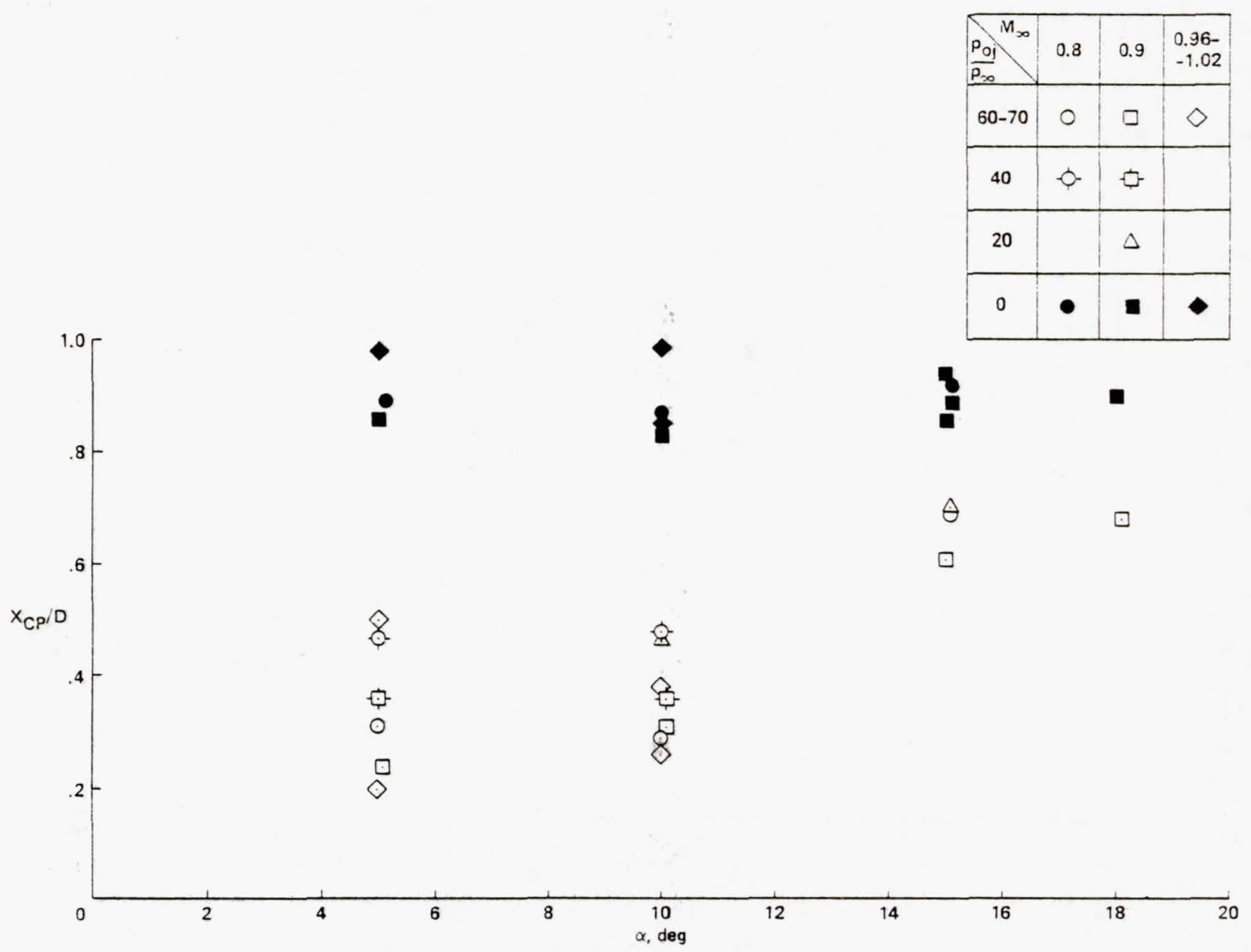

Eig. 17 Center-of-pressure location variation with angle of attack. 


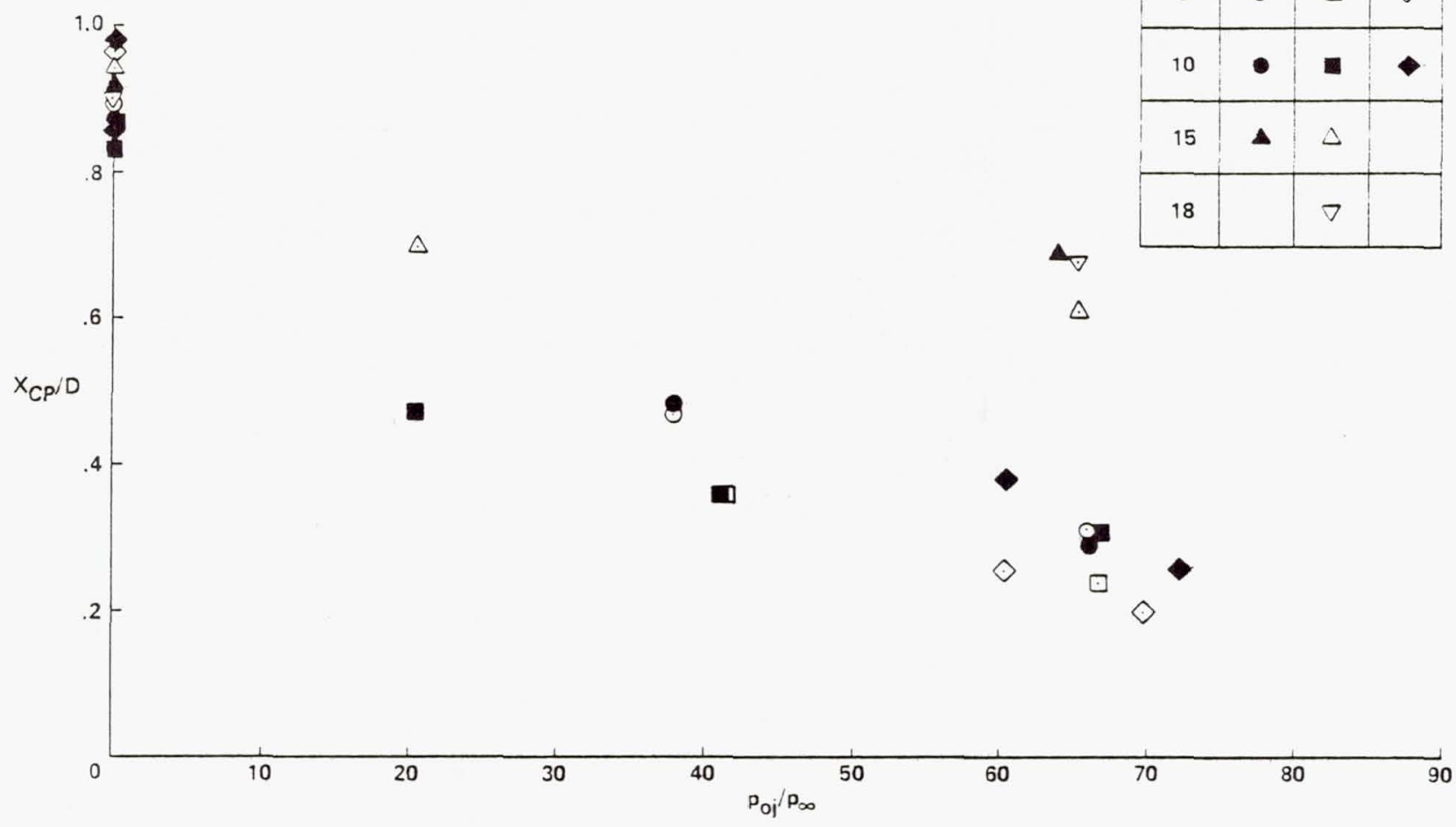

Fig. 18 Pressure-ratio effects on the center-of-pressure location. 

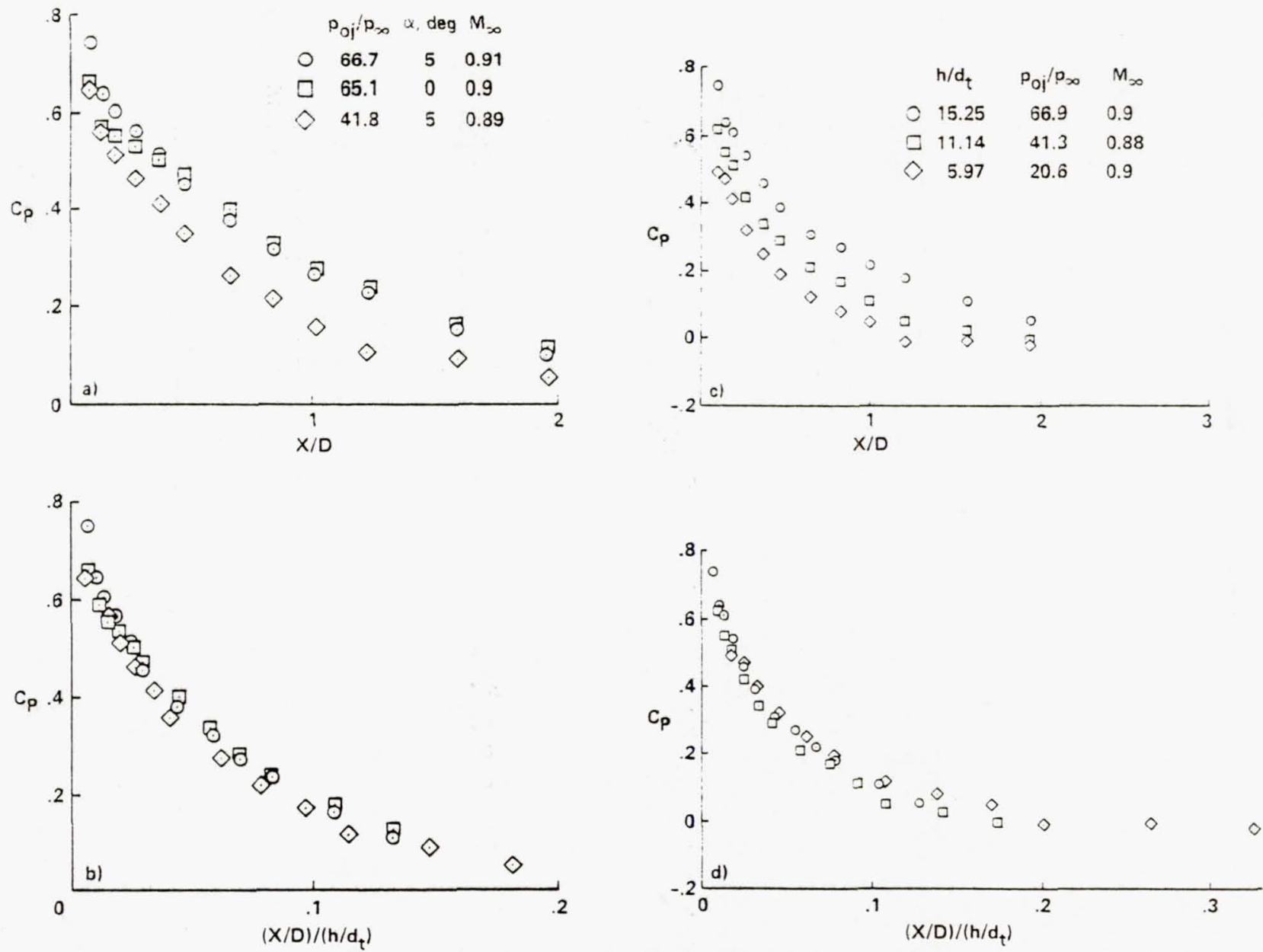

Fig. 19 Pressure distributions normalized by penetration height: (a) Not normalized, $y^{\circ}=0^{\circ}$ and $5^{\circ}$; (b) Normalized, $x=0^{\circ}$ and $5^{\circ}$; (c) Not normalized, $x=10^{\circ}$; (d) Normalized, $x=10^{\circ}$.

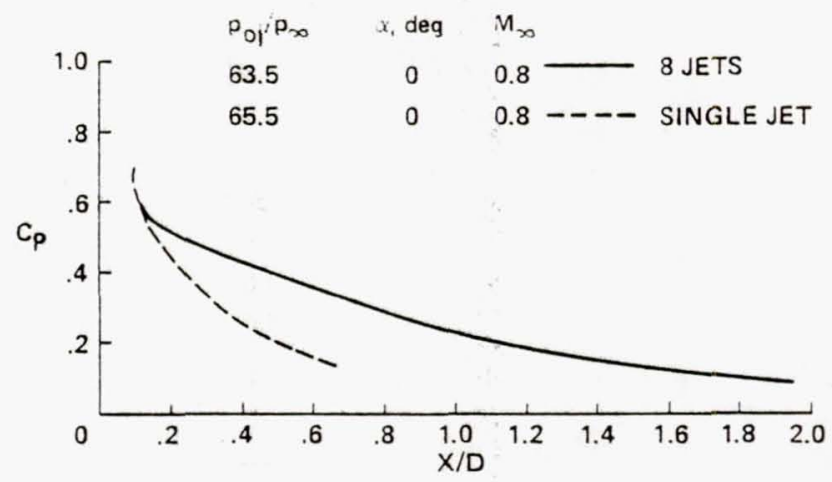

Fig. 20 Pressure distributions of a single jet and of eight jets. 

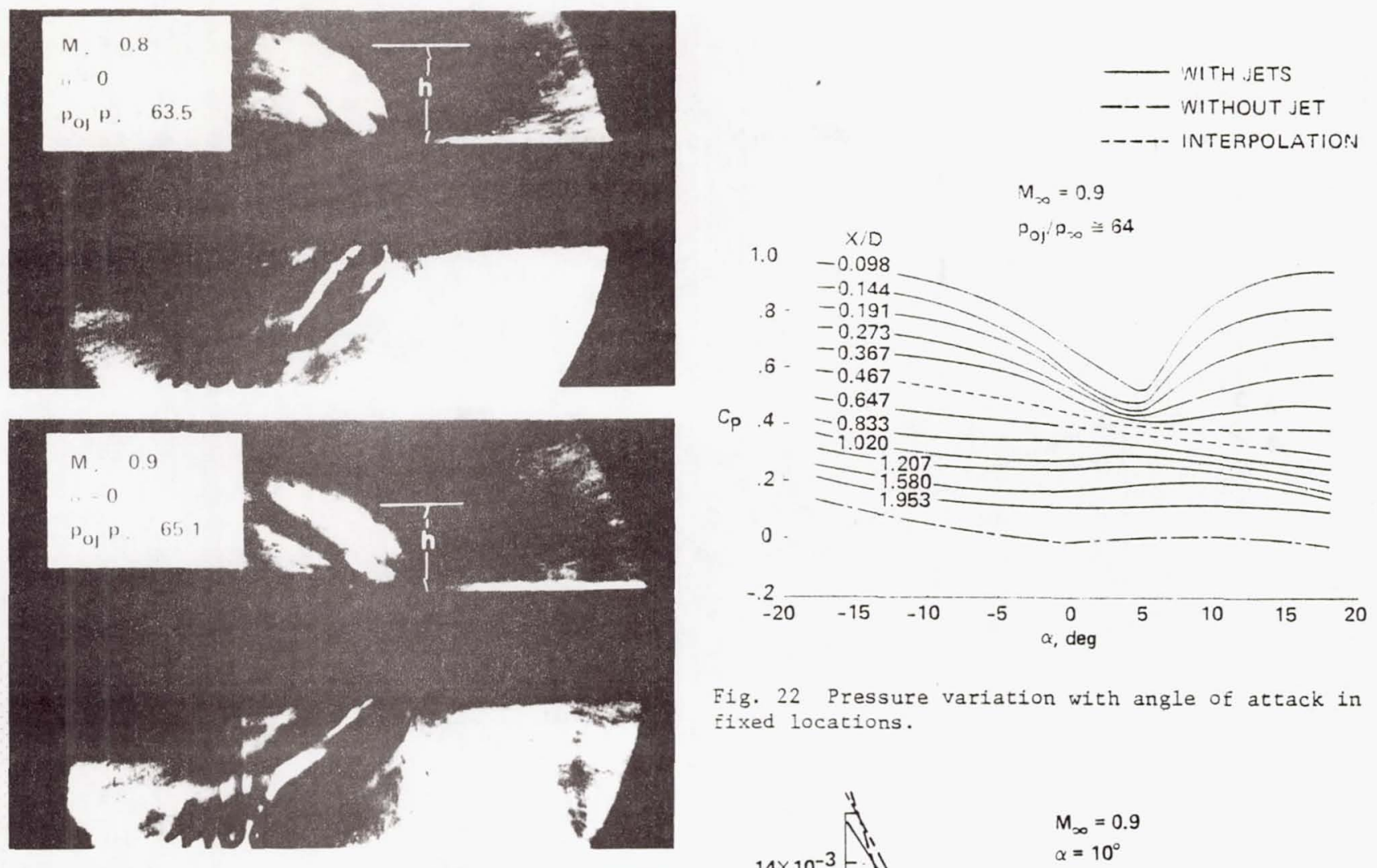

Fig. 22 Pressure variation with angle of attack in fixed locations.

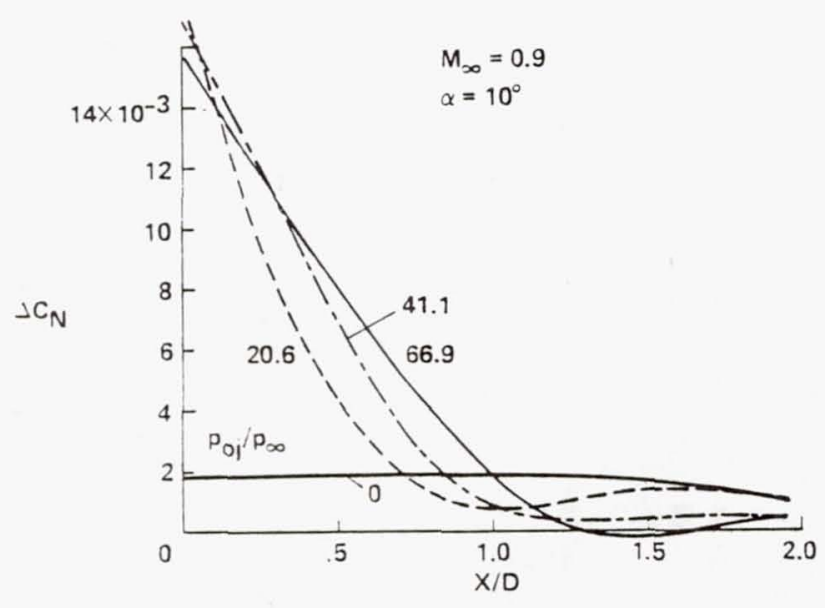

Fig. 21 Schlieren photographs of the eight-jetinduced klow tield.

Fig. 23 Normal-force-coefficient distribution variation with injection pressure ratio.

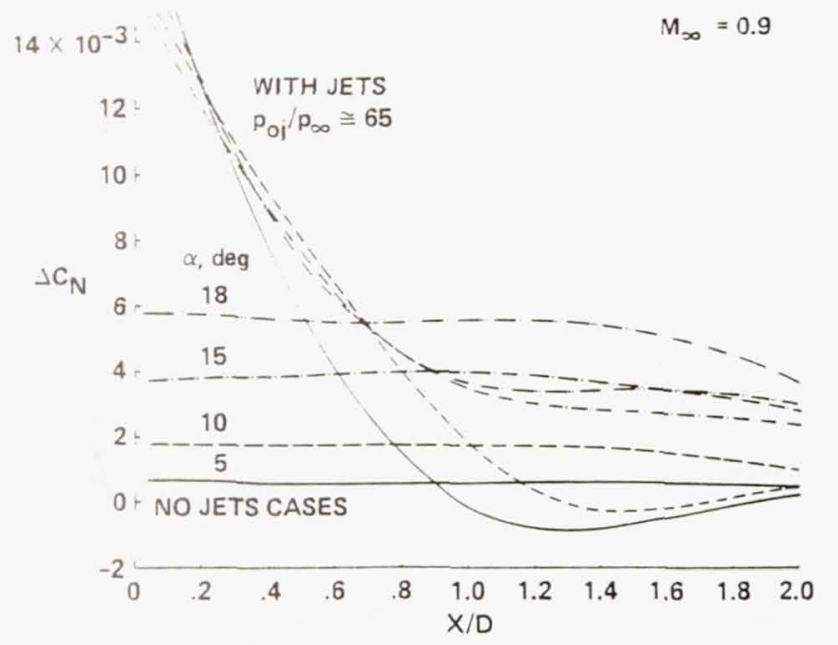

Fig. 24 Normal-force-coefficient distribution variation with angle of attack. 


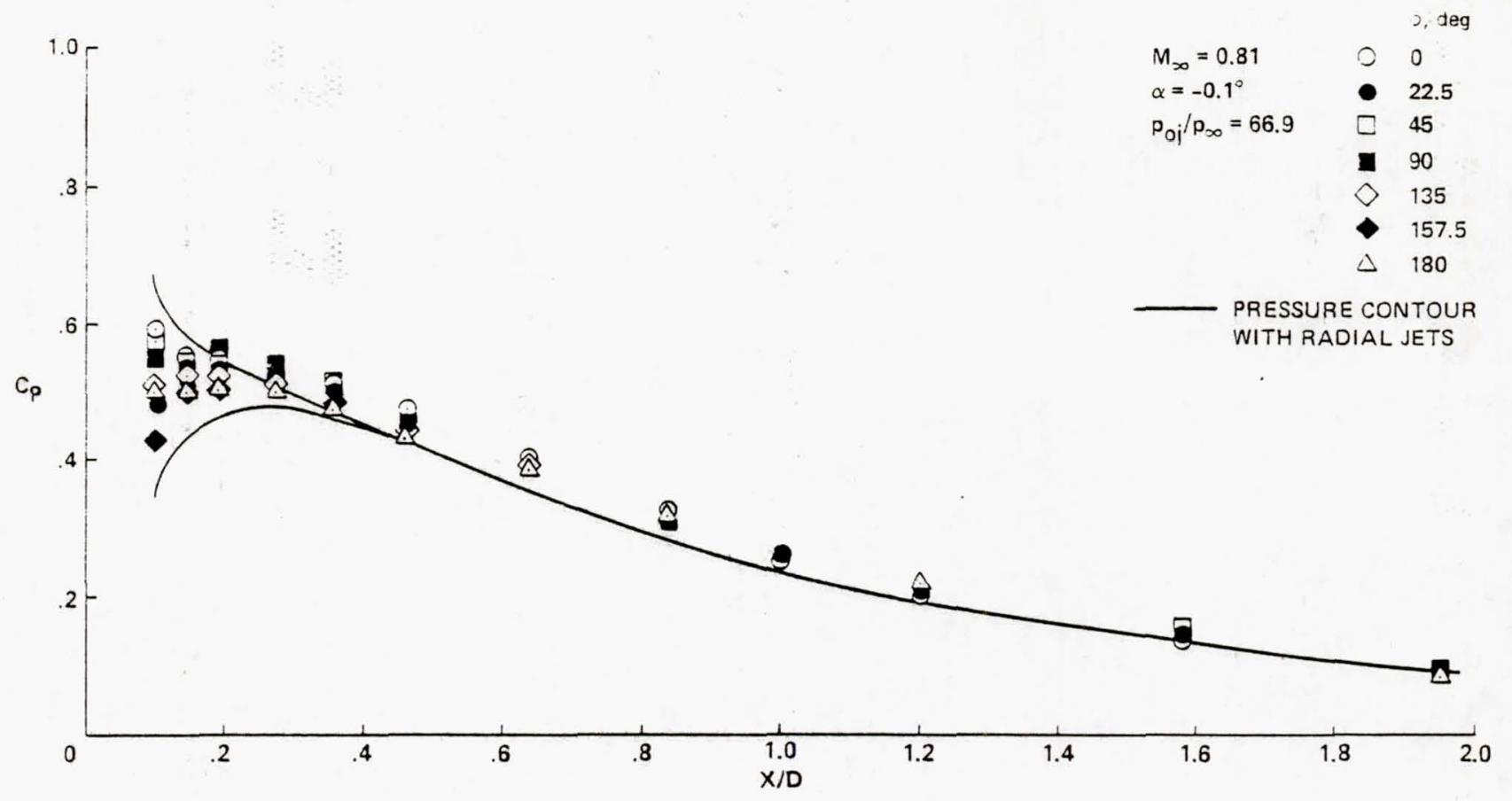

(a) Pressure distribution at $\alpha \cong 0^{\circ}$.

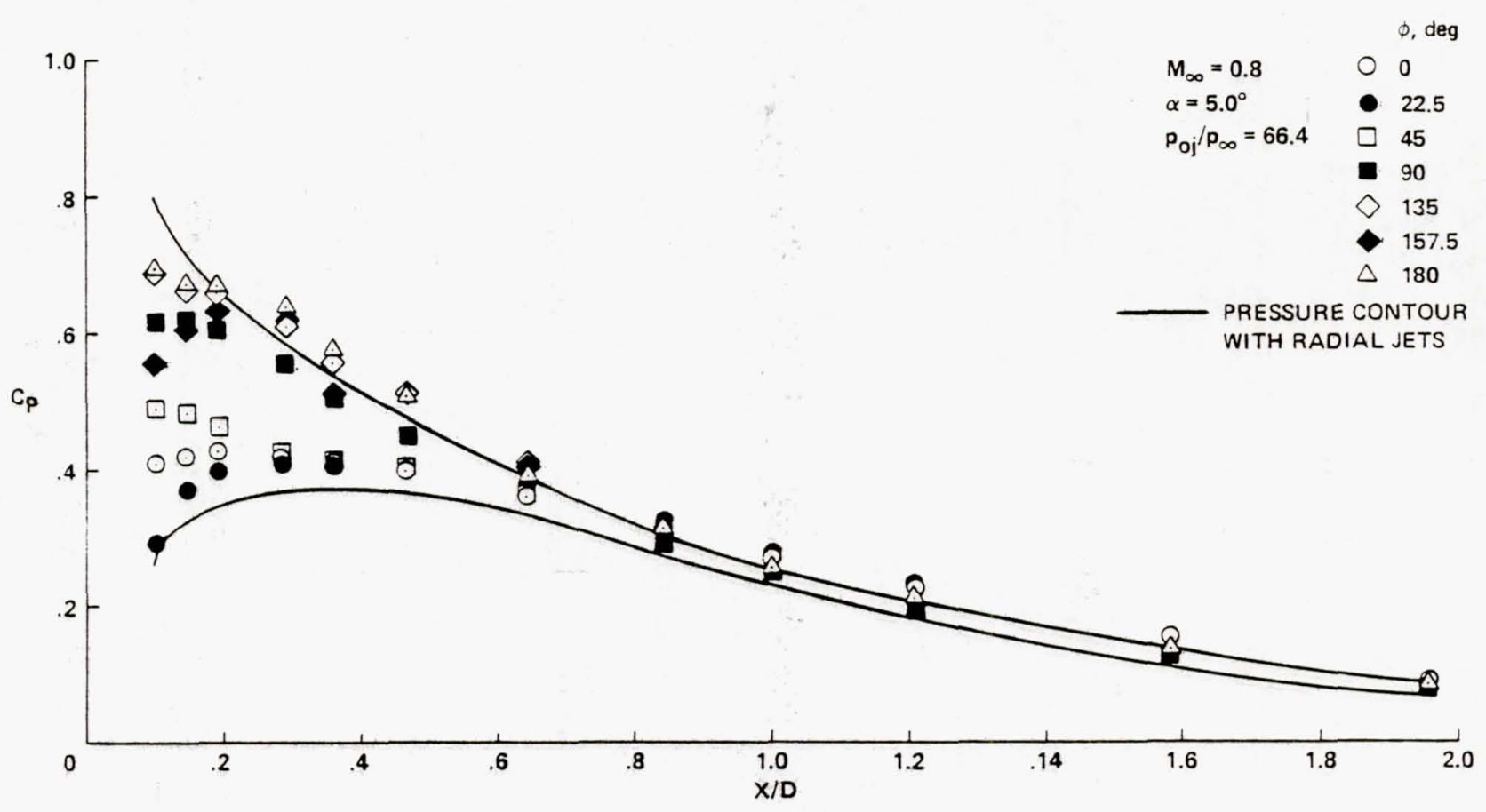

(b) Pressure distribution at $\alpha=5^{\circ}$.

Fig. 25 Comparison of tangential injection with radial injection. 


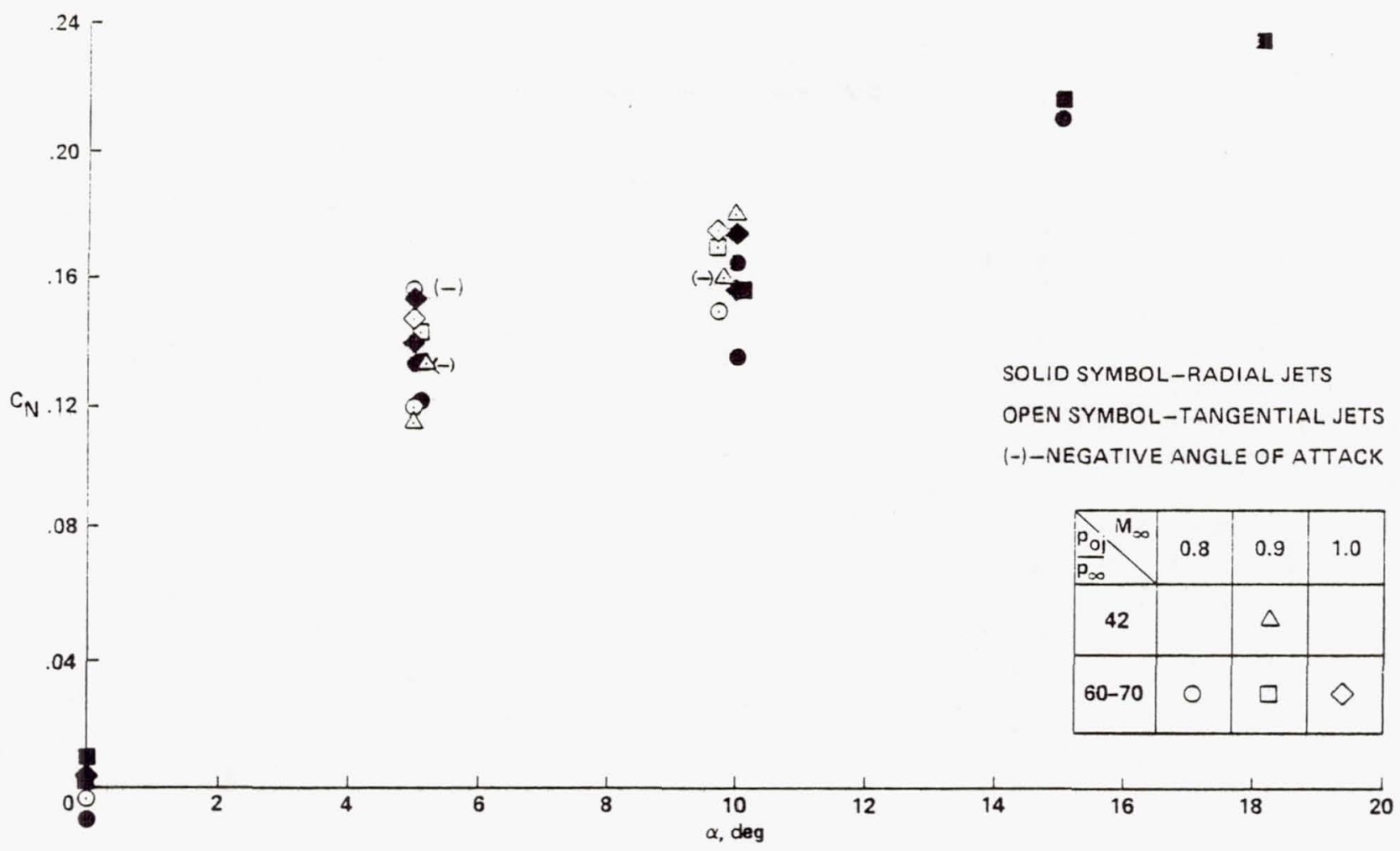

(c) Normal-force-coefficient variation with angle of attack.

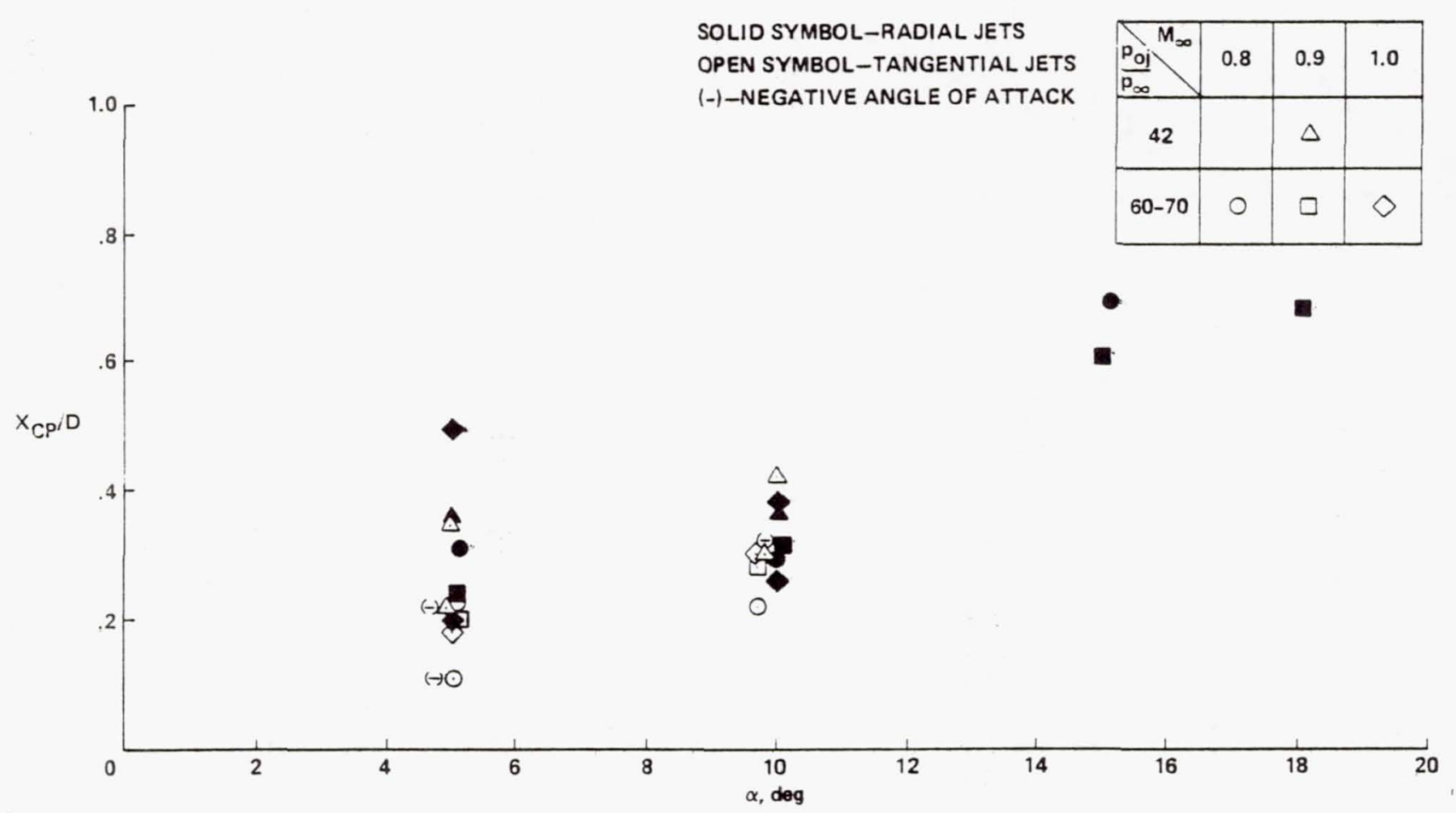

(d) Center-of-pressure location variation with angle of attack.

Fig. 25 Concluded. 


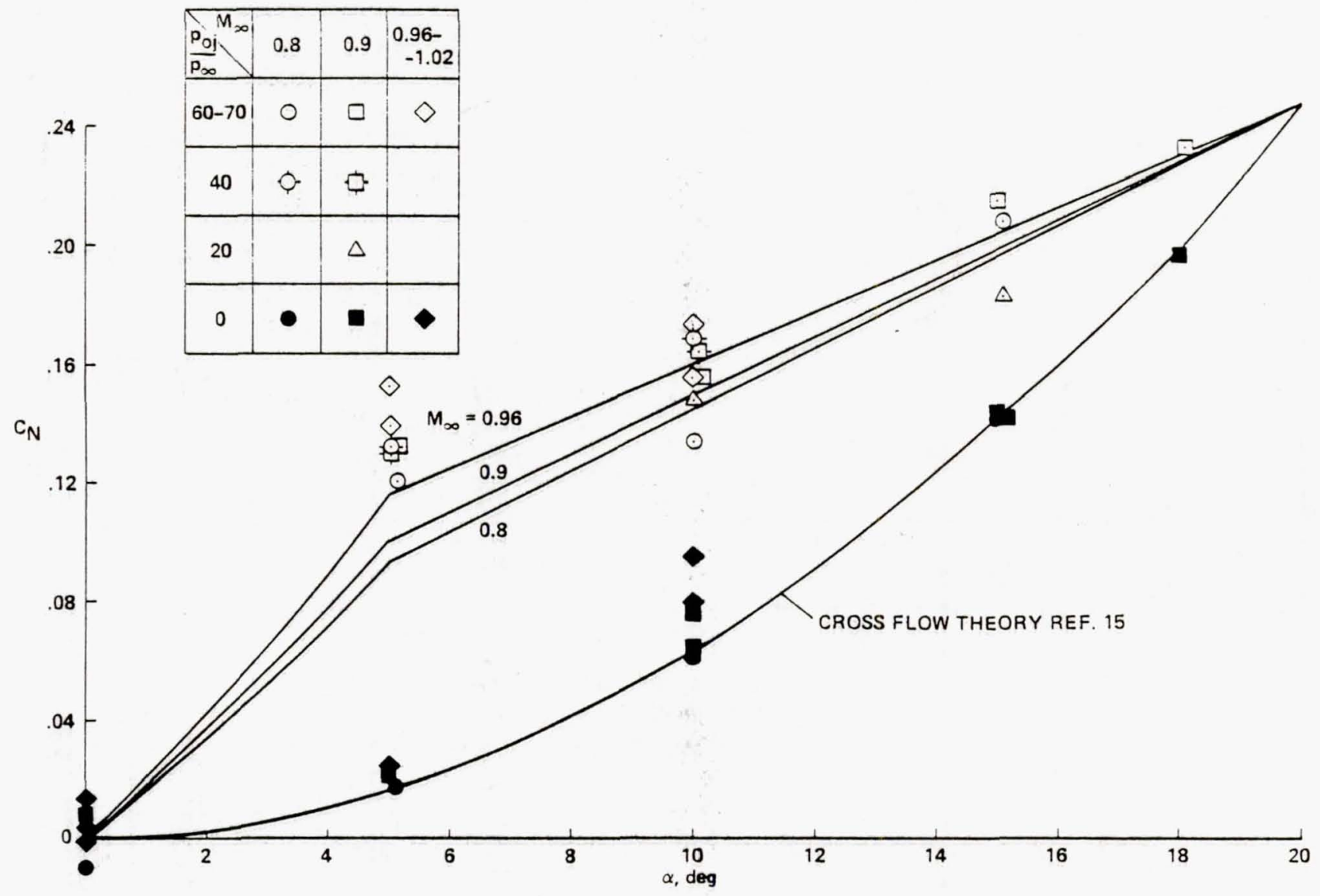

Fig. 26 Comparison of estimated normal-force coefficient with experimental data. 


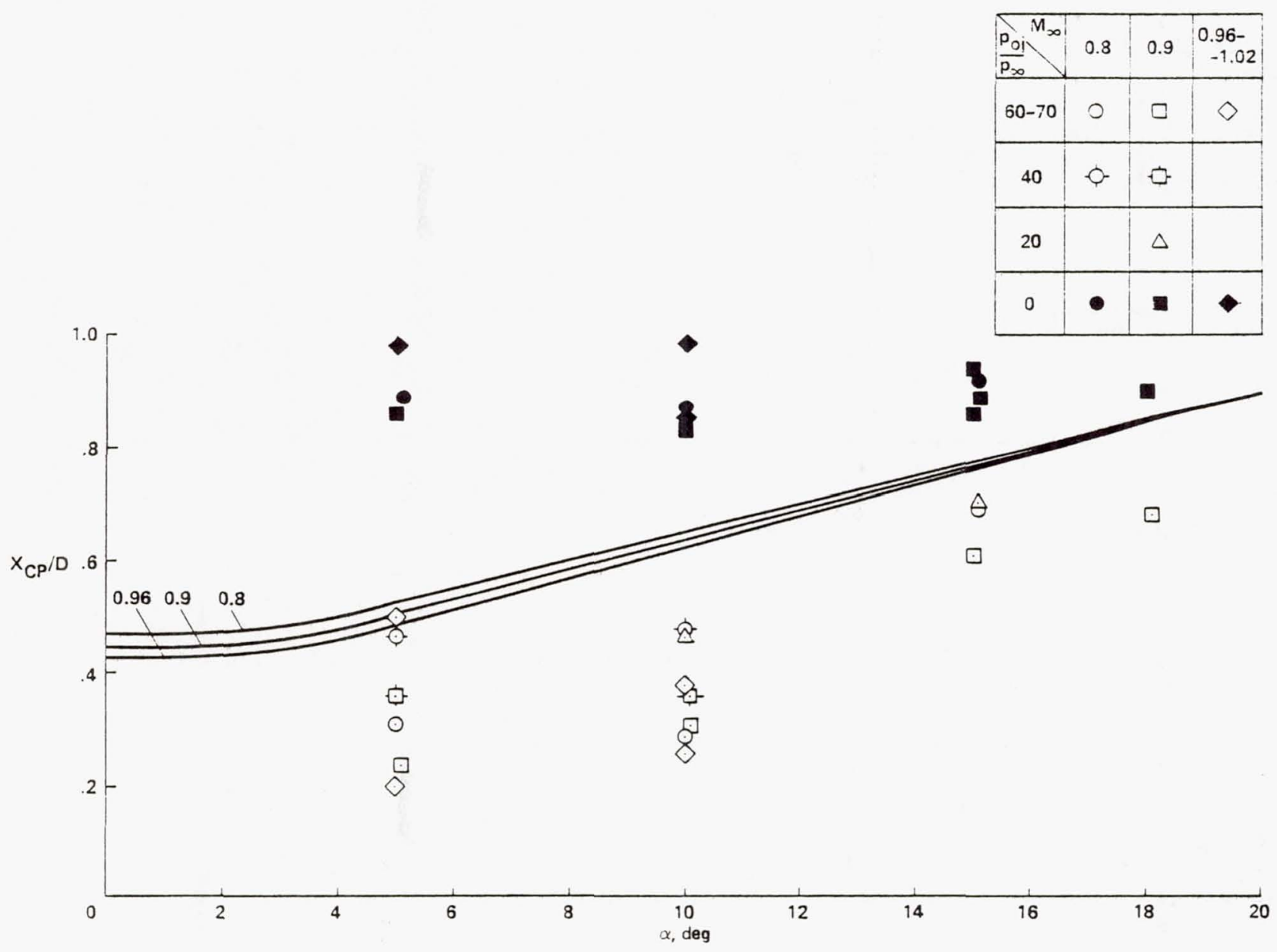

Fig. 27 Comparison of estimated center-of-pressure location with experimental data. 


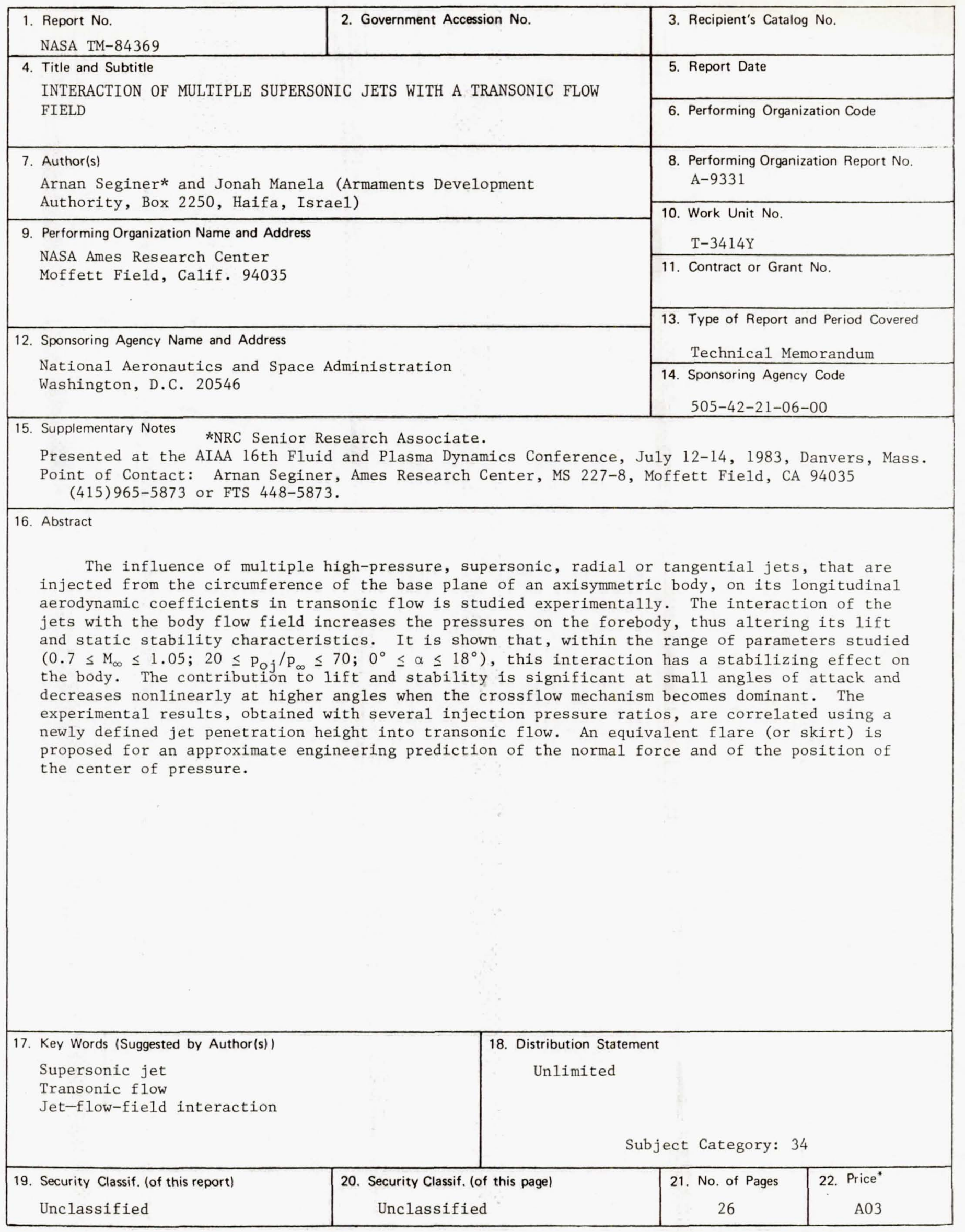

*For sale by the National Technical Information Service, Springfield, Virginia 22161 
